\title{
Effect of size, content and shape of reinforcements on the behaviour of Metal Matrix Composites (MMCs) under tension
}

\author{
A. Paknia ${ }^{1}$, A. Pramanik ${ }^{1 *}$, A.R. Dixit ${ }^{2}$, S. Chattopadhyaya ${ }^{2}$ \\ ${ }^{1}$ Department of Mechanical Engineering, Curtin University, Bentley, WA, Australia \\ ${ }^{2}$ Department of Mechanical Engineering, Indian School of Mines, Dhanbad-826004, Jharkhand, India.
}

\section{*Corresponding author}

Phone: +61 89266 7981, Fax: +61 89266 2681, Email: alokesh.pramanik@ curtin.edu.au

\begin{abstract}
The objective of this research is to investigate the mechanical behaviour of Metal Matrix Composites (MMCs) 6061aluminum, reinforced with silicon carbide particles, under unidirectional tensile loading by finite element analysis. The effects of particle's shape, size and content on the tensile properties of the composites were studied and compared with each other. In addition, stress and strain distributions and possible particle fracture or debonding were investigated. It was found that, among different shapes, a certain shape of reinforcement particle provided better tensile properties for MMCs and, within each shape category, composites with smaller particle size and higher particle content $\underline{(20 \%)}$ also showed better properties. It was also found that when the reinforcement content was $\underline{10 \%}$, the effects of shape and size of the particles were negligible. Not only interfacial length between the reinforcement and matrix materials, but also state of matrix material, due to the presence of the reinforcement particles, affected the stiffness of the MMCs. In almost all of the cases, except for MMCs with triangular particles, when the stress increased, with the increase of the applied positive displacement, the stress distributions remained unchanged.
\end{abstract}

Keyword: Particle reinforcement, shape effect, tensile loading, stress-strain distribution

\section{Introduction}

MMCs, particularly aluminium-based particle/fibre-reinforced composites have a high strength to weight ratio and wear resistance. Ceramic fibre/particulate/whisker reinforced metal matrix composites (MMCs) have had increased applications due to their improved mechanical properties (e.g. improved strength, stiffness and wear resistance) over unreinforced alloys. The demand of new 
industrial applications for high performance composite materials has driven research efforts in the field of Materials Engineering (Huang and Bush 1997). For example, the low wear resistance of aluminium alloy can be overcome by addition of ceramic particles, such as $\mathrm{SiC}$ or $\mathrm{Al}_{2} \mathrm{O}_{3}$. Aluminium alloy based MMC is desirable because of its lower density, increased toughness and corrosion resistance in harsh environmental conditions (Rahimian, Parvin et al. 2010).

Mechanical properties of MMCs have been studied for several decades by using numerical methods as well as experimental analyses for prediction of the overall properties of composites. Prabu et al., (Prabu, Karunamoorthy et al. 2004) developed a 2D microstructure-based FEA models to study the mechanical behaviour of MMC. Their model took into account the randomness and clustering effects or the particle arrangement on stress-strain response and the failure behaviours. Huang et al., (Huang and Bush 1997) used FEA to evaluate the elastic and plastic properties of aluminium/alumina composite materials with ultrafine microstructure and the matrix material was found to be an important factor influencing the mechanical properties of the composites.

Yan et al.,(Yan, Geng et al. 2007) used finite element method to investigate the effect of particle size on the deformation behaviour of the MMCs. Their results indicated that, at a constant particle volume fraction, there was a close relationship between the particle size and the deformation behaviour of the composites. Several studies investigated the effect of reinforcement particle size on the mechanical properties of $\mathrm{Al}-\mathrm{SiC}_{\mathrm{p}}$ composites. Varma et al., (Varma, Kamat et al. 2001) explored low strain yielding behaviour of $\mathrm{SiC}_{\mathrm{p}}$ reinforced $\mathrm{Al}-\mathrm{Cu}-\mathrm{Mg}$ alloy matrix composites with varying reinforcement sizes, such as $1.4,15.8$ and $62.8 \mu \mathrm{m}$ under controlled strain deformation of $1.5 \%$ in both tension and compression. The actual yielding in all the MMCs occurred at lower stress levels in compression than in tension. These were attributed to the distribution of residual stresses in the matrix of MMCs generated due to the large difference in coefficient of thermal expansion between the matrix and the reinforcement.

Wang et al., (Wang, Song et al. 2011) studied the effects of particle size and distribution on the mechanical properties of the $\mathrm{SiC}$ particle reinforced $\mathrm{Al}-\mathrm{Cu}$ alloy composites. It was shown that the small ratio between matrix/reinforcement particle sizes and increased mixing time provided more uniform distribution of the $\mathrm{SiC}$ particles in the matrix. This distribution resulted in higher yield strength, ultimate tensile strength and elongation. Yield strength and ultimate tensile strength of the composite increased with the decrease of particle size while the elongation decreased along with particle size. Ductile fracture of the matrix accompanied by the "pull-out" of the particles from the matrix occurred when reinforced particles were smaller. However, dominant fracture mechanism of 
the composites with larger particles was ductile fracture of the matrix, accompanied by the SiC particle fracture. Chawla et al., (Chawla, Andres et al. 1998) studied SiC volume content and particle size on the fatigue behaviour of $2080 \mathrm{Al}$ alloy. They found that the increase of volume content and decrease of particle size, resulted in an increase in fatigue resistance.

Hall et al., (Hall, Wayne Jones et al. 1994) studied the effects of particle's size, volume fraction and matrix strength on the stress-controlled axial fatigue behaviour and the probability of particle fracture for 2124 aluminium alloy, reinforced with $\mathrm{SiC}$ particles. It was noted that the strength and fatigue life increased with the decrease of particle size and increase of volume fraction. The frequency of particle fracture during crack propagation was found to be dependent on matrix strength, particle size and volume fraction and maximum crack tip stress intensity. Although composites reinforced with smaller particles possessed better mechanical properties, larger reinforced particles gave better mechanical results in some cases. Ganesh et al., (Ganesh and Chawla 2004) investigated extrusion-induced particle-orientation on the mechanical behaviours of metal-matrix composites and noted that the composites demonstrated higher Young's modulus and tensile strength along the longitudinal direction (parallel to the extrusion axis) than that in the transverse direction. The range of anisotropy increased with the $\underline{20 \%}$ volume content, due to the effect of the $\mathrm{SiC}$ reinforcement that increased the Young's modulus and tensile properties.

The above discussion clearly shows that there are huge researches on the effects of reinforcements on mechanical properties of MMCs. While some of these effects were consistent in different studies However, inconsistencies about the effects of the reinforcement particle' size, on the behaviour of the particle reinforced MMCs, were experienced by O’Donnell et al., (O'Donnell and Looney 2001) and Narayanasamy et al., (Narayanasamy, Ramesh et al. 2009) which were due to the other dominant factors. In addition, the distribution of stress and strain under uniaxial tension was never investigated for different size, content and shape of reinforcements though, these are imperatively needed for a better design of MMCs. To address the above issues this research modelled and investigated MMCs with four different reinforcement particle shapes and each shape with three different sizes and also three different reinforced contents. The stress distributions in MMCs and their vector directions in the vicinity of the reinforcement particles were also investigated. From this data, composites with different shapes, sizes and percentages of reinforcement particles were compared with each other, based on their mechanical properties. These results can assist manufacturers to have reliable data about the MMC's behaviours for any future improvements.

\section{Finite element modelling}


Total thirty six study cases were considered in this investigation. For the ease of comparison between the results, the size of the MMC blocks remained constant. All the finite element models had a homogeneous distribution of reinforcement particles which gave the best results, exclusive of homogeneity variable that could sway the judgement about the particle's shape, size and content effects. The finite element software, ANSYS, was used to develop the models and generate the results. Composites with three different sizes of circular SiC particles, with 6, 12 and $24 \mu \mathrm{m}$ in diameter, were modelled. Also, for each particle size three different contents of 10\%, $15 \%$ and $20 \%$ were considered. Total of nine study cases were created for MMCs with circular particles. For other shapes, the area of the reinforcement particle remained constant (= area of the circular particle), and the lengths of the sides for equilateral triangle, square and rectangle shapes were calculated accordingly. Therefore, all four shapes had the same area but different perimeters. A constant positive displacement was applied on the blocks and the tensile properties under this displacement were explored. As the block size and the displacement were constant, therefore, the macroscopic (overall) strain value in all of the cases remained constant. To induce a tensile force, the block was constrained, on the opposite side of the applied displacement, in Y-axis direction and also to avoid block's sideway movements, a middle node in the same side was constrained in X-axis direction (Fig. 1).
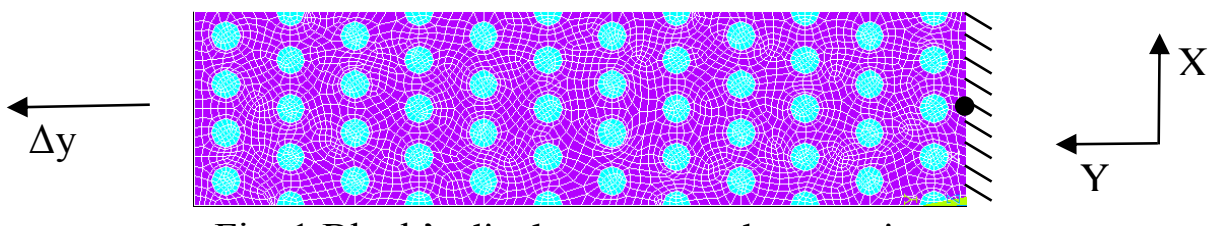

Fig. 1 Block's displacement and constraints

2.1 Number, size and shape of particles in each case study

The dimensions of the tensile blocks were selected as to have the number of particles, in each study case, an integer. This simplified having the exact required volume percentages of the reinforcement particles for the study cases. Based on values in table 1, the area of the tensile block needed to be $27,159 \mu \mathrm{m}^{2}$, from which the block's dimensions were calculated as $329.5 \mu \mathrm{m}$ long and $82.4 \mu \mathrm{m}$ wide. The aspect ratio of 1:3 was selected for the rectangular reinforcement particles. This was based on a reasonable assumption to have a correct shape representation.

\begin{tabular}{|c|c|c|c|c|c|c|}
\hline \multirow{2}{*}{$\begin{array}{c}\text { Reinforcement } \\
\text { content }\end{array}$} & \multicolumn{5}{|c|}{ Diameter of circle $\bigcirc$} & \multicolumn{3}{c|}{ Sides of equilateral triangle } \\
\cline { 2 - 7 } & $6 \mu \mathrm{m}$ & $12 \mu \mathrm{m}$ & $24 \mu \mathrm{m}$ & $8.08 \mu \mathrm{m}$ & $16.16 \mu \mathrm{m}$ & $32.32 \mu \mathrm{m}$ \\
\hline $10 \%$ & 96 & 24 & 6 & 96 & 24 & 6 \\
\hline $15 \%$ & 144 & 36 & 9 & 144 & 36 & 9 \\
\hline $20 \%$ & 192 & 48 & 12 & 192 & 48 & 12 \\
\hline
\end{tabular}




\begin{tabular}{|c|c|c|c|c|c|c|}
\hline \multirow{2}{*}{$\begin{array}{c}\text { Reinforcement } \\
\text { content }\end{array}$} & \multicolumn{5}{|c|}{ Sides of square } & \multicolumn{3}{c|}{ short side of rectangle $\square$} \\
\cline { 2 - 7 } & $5.31 \mu \mathrm{m}$ & $10.63 \mu \mathrm{m}$ & $21.27 \mu \mathrm{m}$ & $3.07 \mu \mathrm{m}$ & $6.14 \mu \mathrm{m}$ & $12.28 \mu \mathrm{m}$ \\
\hline $10 \%$ & 96 & 24 & 6 & 96 & 24 & 6 \\
\hline $15 \%$ & 144 & 36 & 9 & 144 & 36 & 9 \\
\hline $20 \%$ & 192 & 48 & 12 & 192 & 48 & 12 \\
\hline
\end{tabular}

Table 1 Number and size of particles

\subsection{Material Properties}

The MMC work material was a 6061 aluminium alloy, reinforced with silicon carbide particles. The reinforcement was considered as a linear isotropic material, following the generalized Hook's law. The material properties of the particles were: Young's modulus $=400 \mathrm{GPa}$ and Poisson's ratio $=0.17$. For the $6061 \mathrm{Al}$ matrix, a temperature-independent multilinear kinematic hardening material model (available in ANSYS), and its associated flow rule, was used. The properties of the matrix were: Young's modulus $=71.6 \mathrm{GPa}$, yield strength $=125 \mathrm{MPa}$, shear modulus $=1.48 \mathrm{GPa}$ and Poisson's ratio $=0.33$ (Pramanik, Zhang et al. 2007). Fig. 2 represents stress-strain curves included into the analysis for matrix and particles.

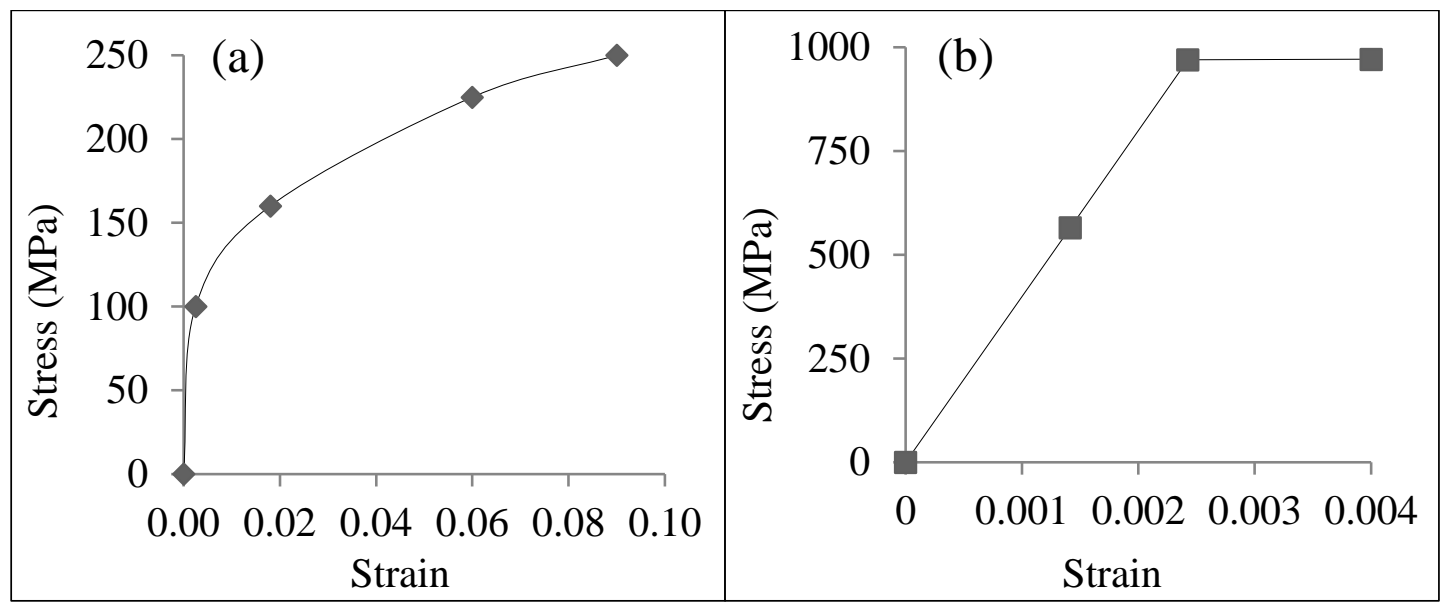

Fig. 2 Stress versus strain curve for (a) aluminium alloy and (b) silicon Carbide particle

\subsection{FEA element type and behaviour}

This study used structural solid Plane183 element for the two dimensional analysis. To understand the effect of the reinforcement particles more easily, plane strain element behaviour was selected in this study. Particles were assumed to be perfectly bonded to the matrix material. The number of steps in ANSYS was determined automatically, according to the convergence results of each model. Composites were modelled and meshed with manual sizing to achieve the best convergence and 
accuracy of the results. The meshed blocks of MMCs with circular reinforcement particles are shown in Fig. 3.
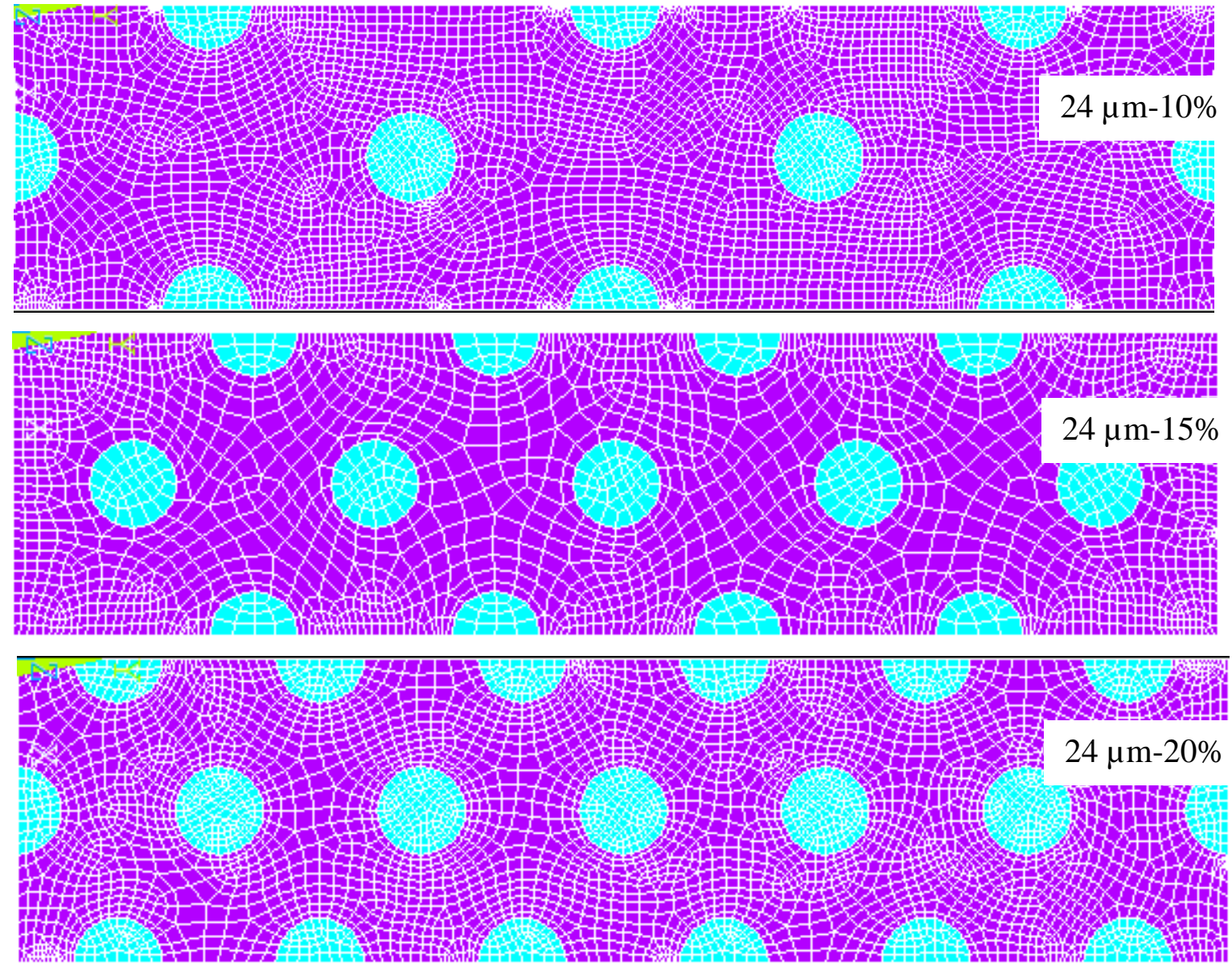

Fig. 3 Meshed case studies - composites with circular particles

\section{Results and analyses}

\subsection{Stress-strain curve}

Stress-strain curve is an extremely important graphical presentation of a material's mechanical properties. It is unique for each material and is found by recording the amount of deformation (strain) at distinct intervals of tensile or compressive loading (stress). In this research, firstly, a number of steps were selected from the total number of the computation steps (Determined by ANSYS). Then their corresponding displacement values were extracted from the software and the strain values were calculated. To calculate the average stress of the whole block at each of these steps, the partial reaction forces of all nodes at the restrained side of the block were extracted from the software and added together to obtain the total reaction force, that was induced by a known displacement (strain) value in that step. This forces were divided by the width of the sample block to calculate the average tensile stresses at various steps, with known strain values. By using these two sets of stress and strain values, 
the Stress-strain curves were plotted for each study case. The displacement was selected $+20 \mu \mathrm{m}$; therefor total strain was calculated from equation 1 :

$\varepsilon=\frac{\Delta l}{l}$

Where $l$ equalled the length of the sample block.

$\varepsilon=\frac{20}{329.5}=0.06$

\subsubsection{Effect of reinforcement content}

The effects of the volume percentages of the reinforcement particles, on the stress-strain curves, are shown in Figs. 4 for circular, triangular, square and rectangular particles. All these graphs suggest that the stiffness of the composites was higher than that of matrix materials. The stiffness of MMCs increased with the increase of the reinforcement content. For all types of MMCs considered in this study, the variation in the stiffness was wider when the size of the reinforcement particles was smaller. When the size of the particles was smaller consequently, the total surface between the matrix and particles increased. As the total surface of contact increased, more loads were transferred to the reinforcement particles and consequently, the total stiffness of the composites increased. This explains the wider variation of stiffness in MMCs with smaller particles. It is also interesting to note that the variation of the stiffness consistently increased when the shape of the reinforcement changed from circle to triangle to square and to rectangle. However, MMCs with the rectangular particles (Fig. 4 (g)) showed almost similar trend to that of MMCs with the square particles (Fig. 4 (e)). This increase was due to the effect of the shape of the particle on the total surface of contact which was also investigated separately.

\subsubsection{Effect of size}

The effect of the size of the reinforcement particles on the stress-strain curves are shown in Figs. 5 for circular, triangular, square and rectangular particles. These graphs show that effects of the size of the reinforcement particles could not be distinguished when the content of the particles was low (10\%). The size effect became prominent when the reinforcement content increased. At higher reinforcement content (20\%), the stiffness increased widely with the decrease of the size of the particles. The variation of the stiffness of the MMCs became wider when the shape of the reinforcements changed from circle to triangle to square and to rectangle. However, MMCs with the rectangular particles (Fig. 5 (h)) showed similar trend to that of MMCs with the square particles (Fig. 5 (f)). This increase in the variation was due to the increase of the particle's perimeter and consequently, increase in the total 
surface between the matrix and particles. As the total surface of contact increased, more loads were transferred to the reinforcement particles and the total stiffness of the composites increased. 


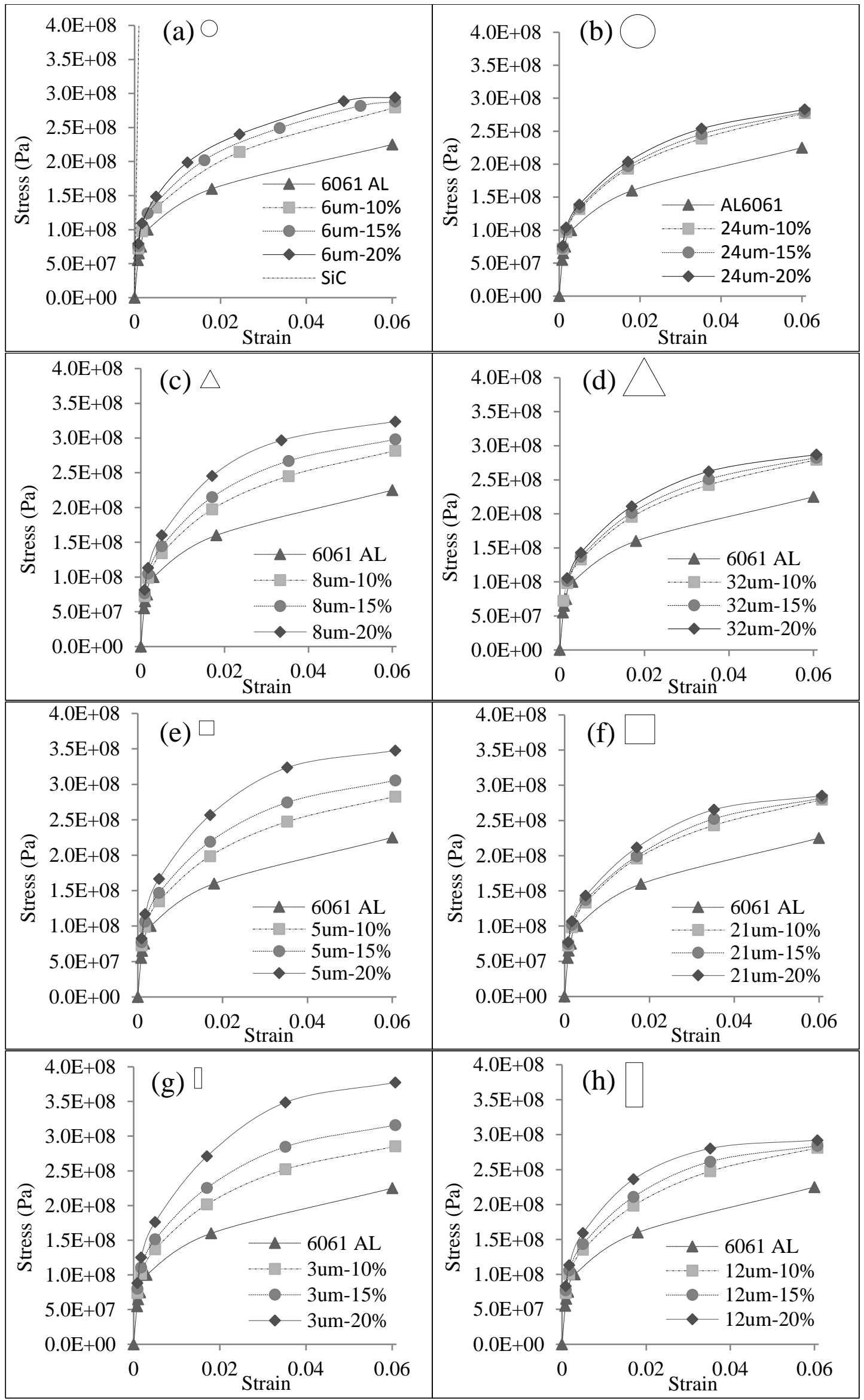

Fig. 4 Stress-strain curves for composites with minimum and maximum particle sizes 


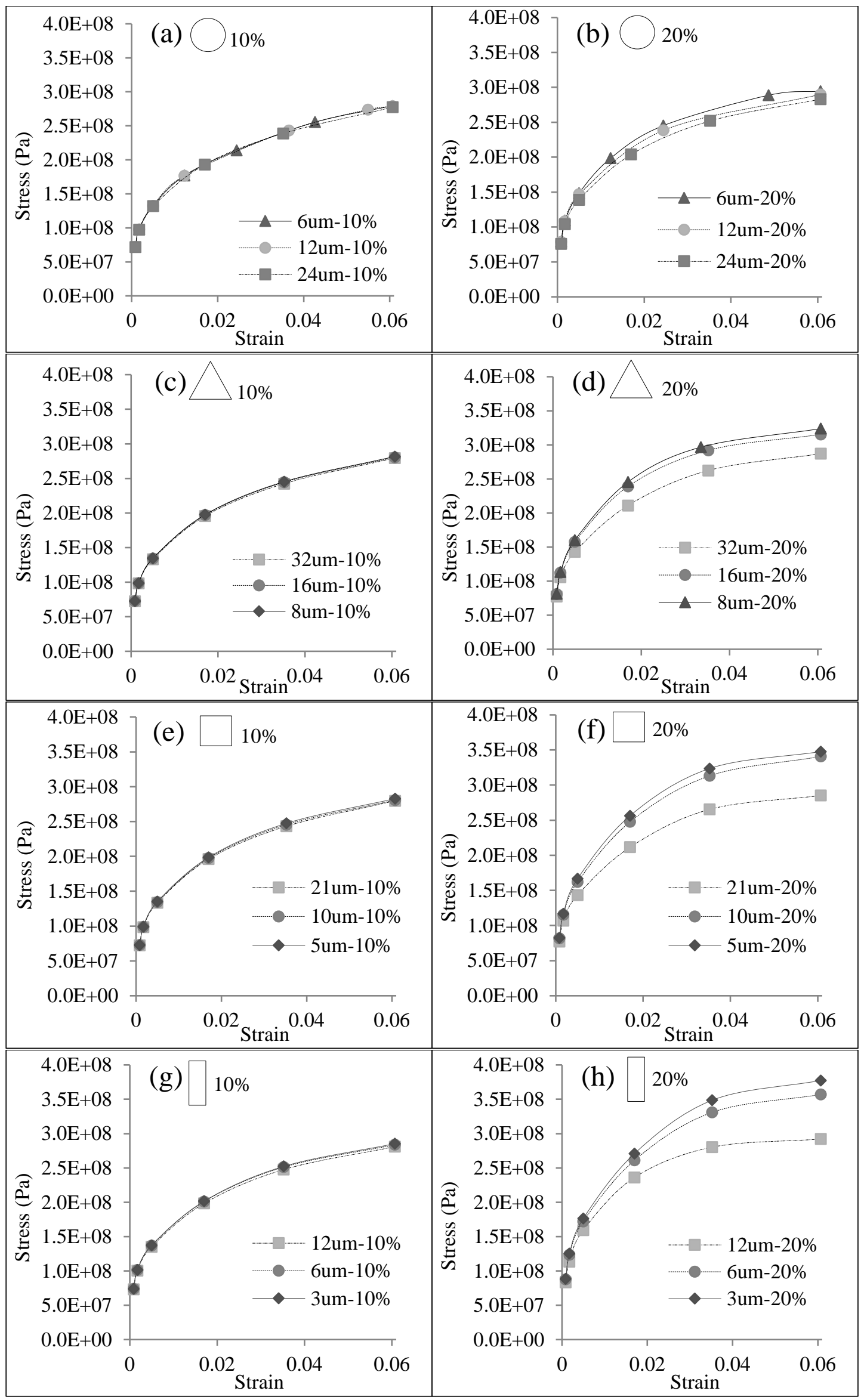

Fig. 5 Stress-Strain curves for composites with $10 \%$ and $20 \%$ reinforcement contents 


\subsubsection{Effect of shape}

To compare the effects of particle's shape on the stress-strain curves, for all four different shapes, all small particle sizes and all large particle sizes were compared separately in two different volume percentages of $10 \%$ and 20\%. Figs. 6 and 7 represent the stress-strain curves for small and large particles respectively. The figures show that the effects of particle's shape on the stiffness were minor when the reinforcement content was $\underline{10 \%}$. However, at $20 \%$ reinforcement content (Fig. 6 (b)) the effects of particle's shape became clearly visible. As illustrated, the stiffest material was the MMC with rectangular particles followed by square, triangular, and circular particles, in order of decreasing stiffness. Similar effects were noted in composites with large particles, as shown in Fig. 7. The reason of this variation in behaviour can be explained by comparing the strain patterns which were produced by these shapes in the composites, as shown in Fig. 8.

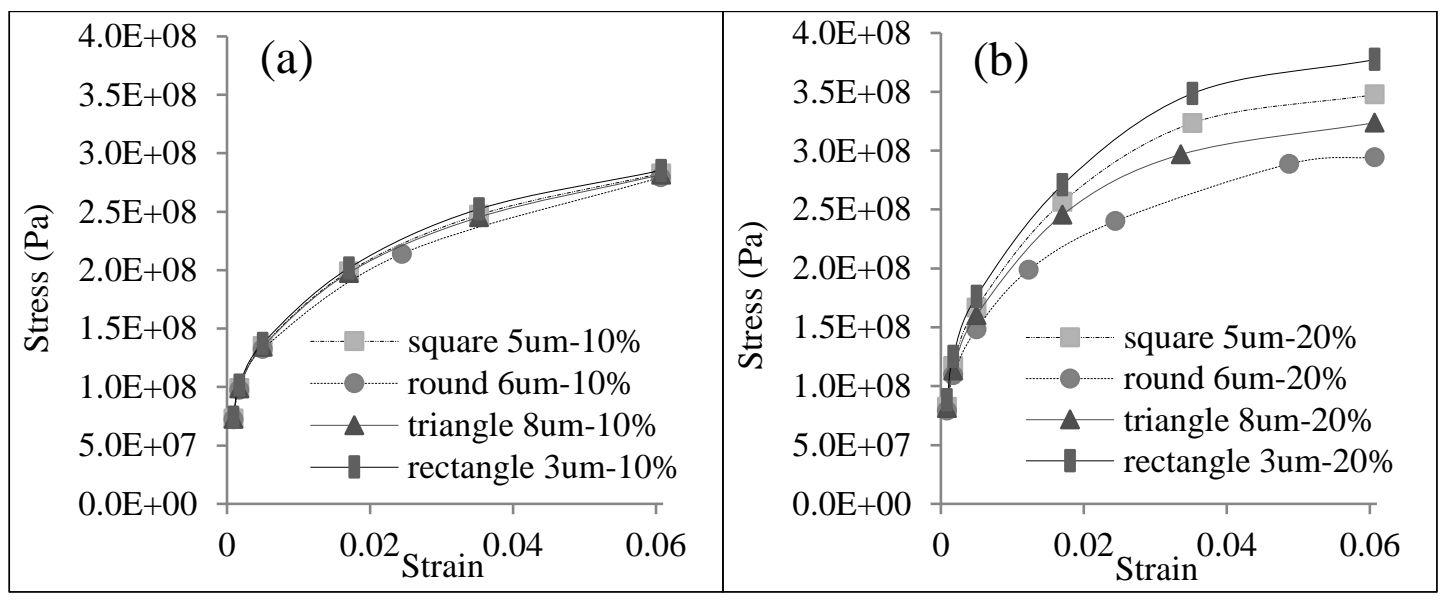

Fig. 6 Stress-Strain curves for MMCs with small particles and (a) 10\% and (b) $20 \%$ contents.

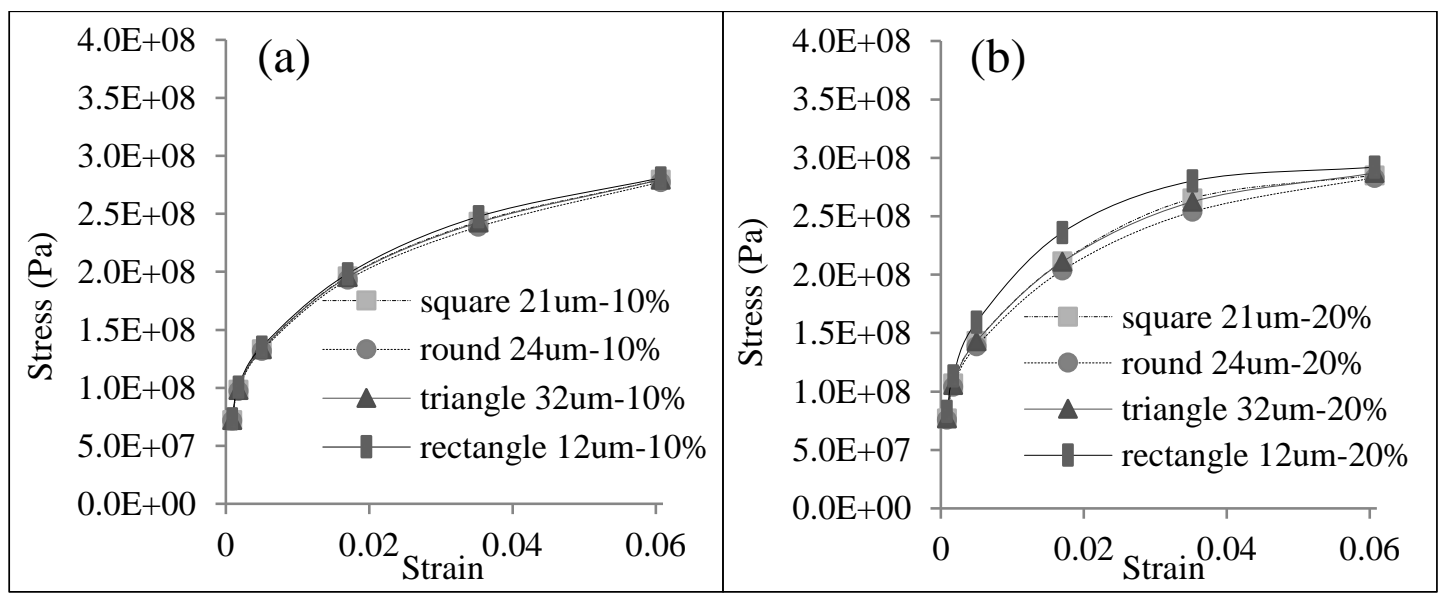

Fig. 7 Stress-Strain curves for MMCs with large particles and (a) 10\% and (b) $20 \%$ contents. 
As shown in Fig. 8, the pattern of the strain field depended on the particle's shape. Where the strain concentrations occurred, they resulted in a less distributed strain pattern around the particle, in the matrix material. Whatever the strain concentrations were bigger, the less widely and broadly, the strain was distributed throughout the composites. The existence of a high strain concentration increased the possibility of the material failure while a well distributed strain pattern indicated higher stiffness in the composites. In Fig. 8 (a) the maximum strain occurred symmetrically at four points of the circular particle. These points were potentially the debonding points in a fracture, occurring at matrix-particle interface and as a result of them, the strain pattern in the matrix material showed lower values, compared to the other shapes. In Fig. 8 (b) the highest strain concentrations occurred in three places, away from the triangular particle, and the overall strain was better distributed compared to the circular particle. In Fig. 8 (c) the highest strain concentrations occurred at two places in matrix, away from the square particle, and also, the distribution of the strain was better than the circular and triangular particles. In Fig. 8 (d) the least strain concentrations and the best strain distribution were observed. The MMCs with rectangular particles experienced highest strain hardening over the wide areas of the matrix material thus, it showed highest stiffness compare to the other shapes of particles. For the same reason, the next high stiffness was seen in the square particle followed by triangular and circular particles.

In addition, the stiffness of the composite can be related to the boundaries around the particles which limit the movements of the dislocations and therefore, produce composite with better tensile properties. These boundaries, with minimal elongation (bluish colours), were maximum for rectangle followed by square, triangle and circle. This also conformed to the stiffness data of these composites.

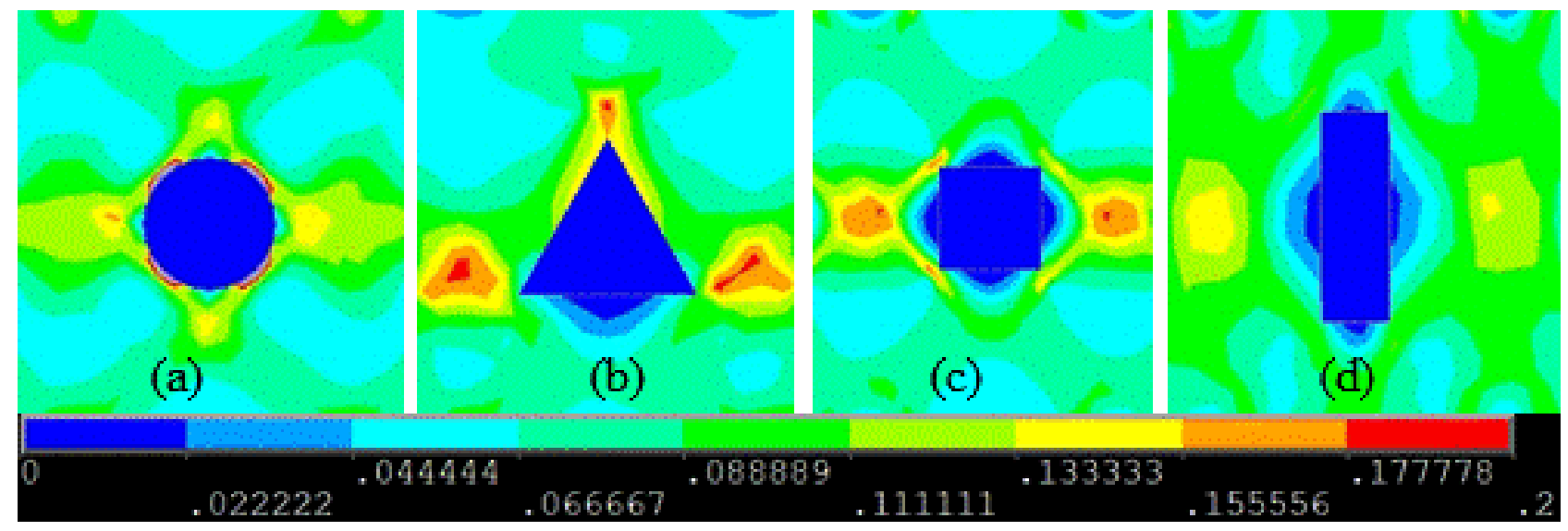

Fig. 8 Von Mises total strain - $15 \%$ medium size particles content

\subsection{Stress variation}


The magnitude and direction of principal stresses, under loading conditions, give indication of possible fracture or particle debonding of MMCs. Therefore, the distribution, direction and magnitude of first and third principal stresses were investigated in and around the particles under the applied displacement.

\subsubsection{Effect of reinforcement content}

To investigate the effect of the reinforcement content on the stress variation, composite with $12 \mu \mathrm{m}$ diametre circular particles was selected and its stress vectors' direction and distribution were investigated at the end of the applied displacement, for $10 \%$ and 20\% reinforcement contents. Fig. 9 shows that the third principal stress was much smaller than the first principal stress and the stresses in the reinforced particles were higher than that of matrix material, irrespective of the reinforcement contents. However, both of the principal stresses increased with the increase of the reinforcement content. This implies as the reinforcement content increased, consequently the stiffness of the composite increased, which resulted in higher stress values.

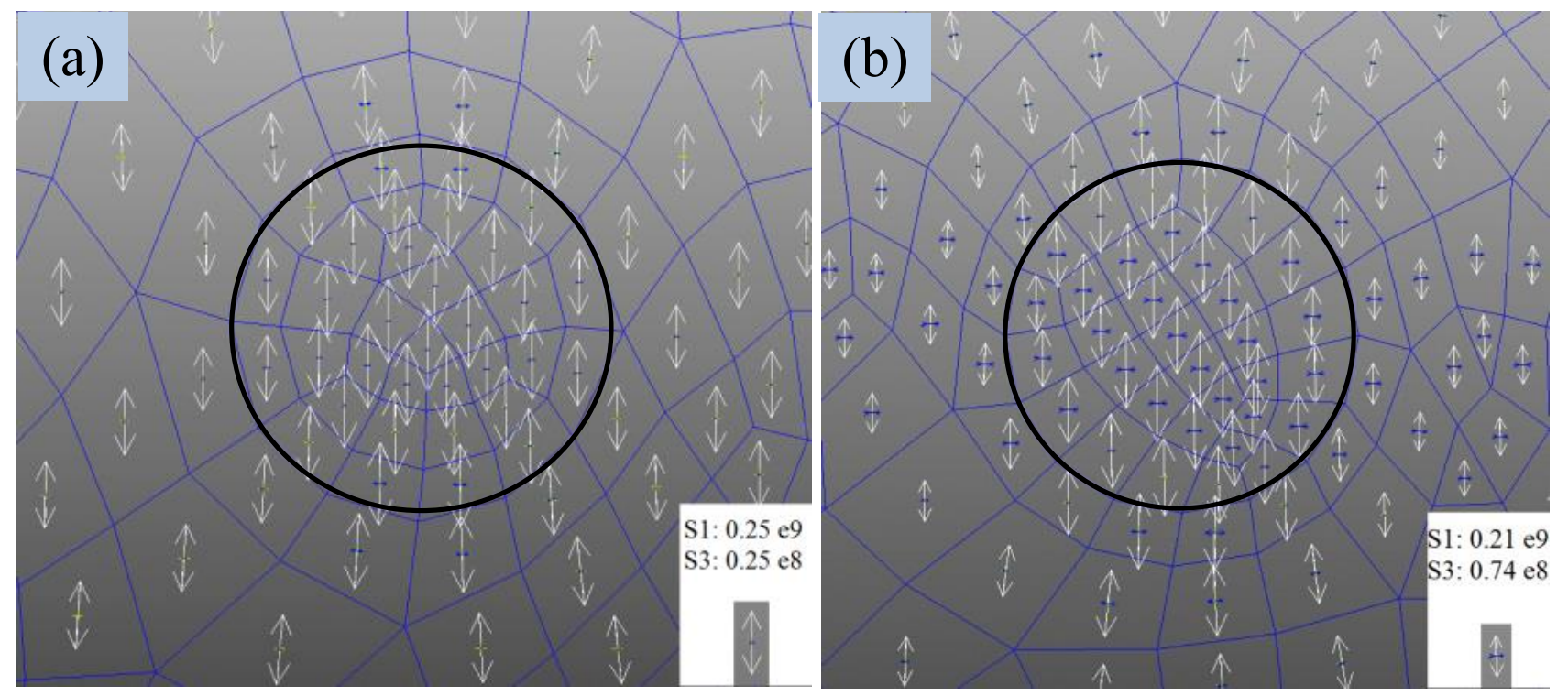

Fig. 9 Stress vector plot for $12 \mu \mathrm{m}$ (a) $10 \%$ and (b) $20 \%$ reinforcement content

\subsubsection{Effect of size}

Fig. 10 shows the effect of particle size on the stress variation, for composites with circular particles and $15 \%$ reinforcement content, at the end of the applied displacement. Fig. 10 shows that the third principal stress was much smaller than the first principal stress and the stresses in the reinforced particles were higher than that of matrix material, irrespective of the size of the particles. As shown in the figures the principal stress magnitudes increased by reducing the particle size. 

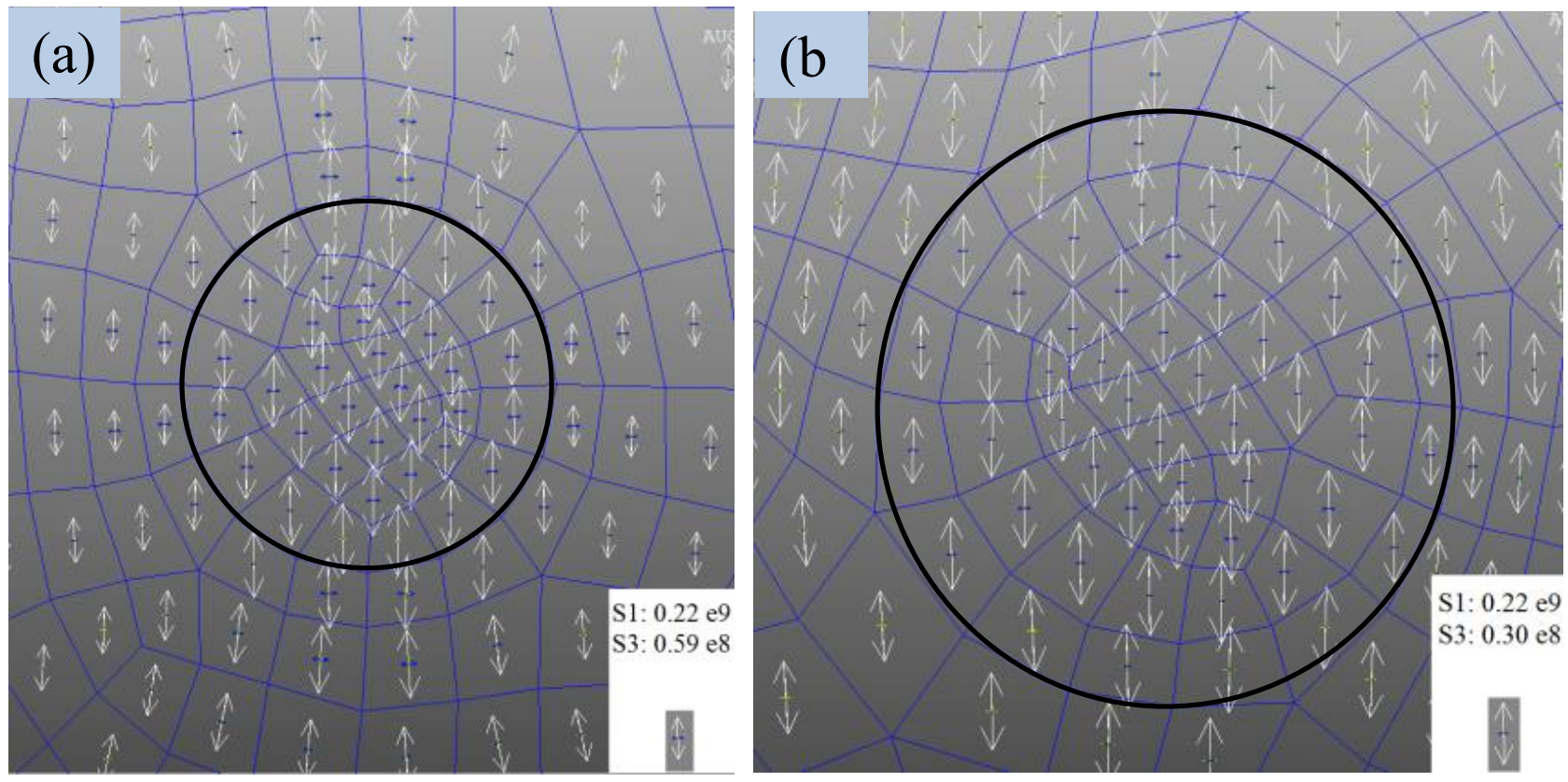

Fig. 10 Stress vector plot for (a) $6 \mu \mathrm{m}-15 \%$ and (b) $24 \mu \mathrm{m}-15 \%$

\subsubsection{Effect of shape}

To investigate the effect of particle's shape, composites with medium size particles and $15 \%$ reinforcement content were selected. The stress vectors' direction and distribution were also shown at three different steps of applied displacement (First, middle and last steps) for all four different particle shapes (Figs. 11, 12, 13 and 14).
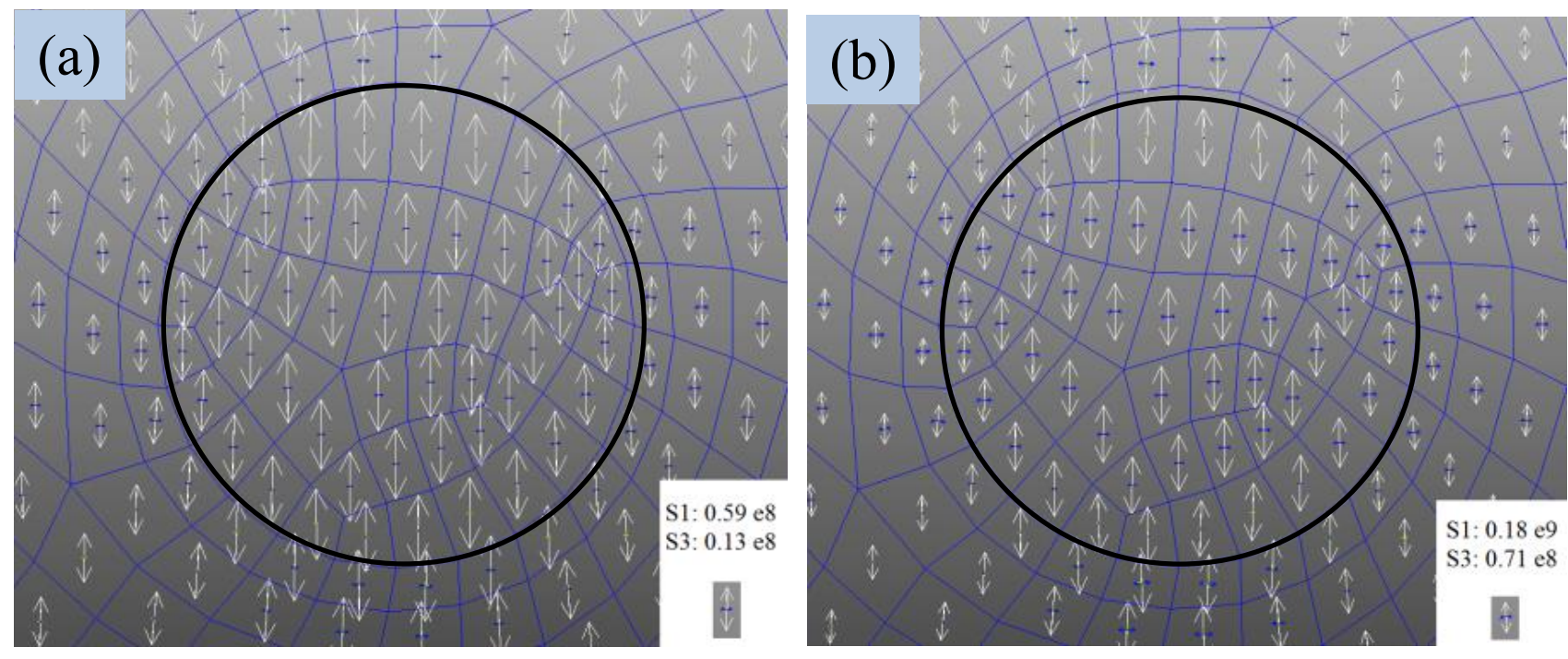


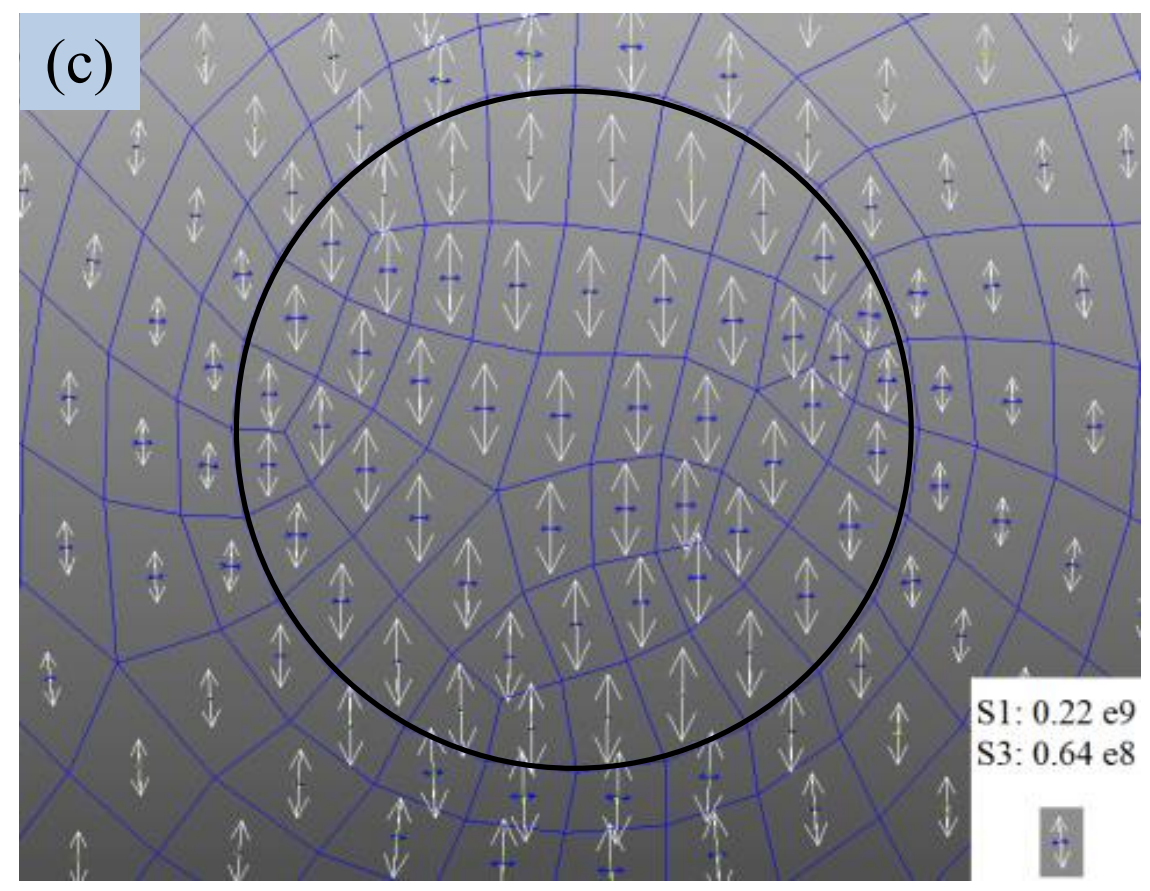

Fig. 11 Stress vector plot for $12 \mu \mathrm{m}-15 \%$ circular particle at (a) $0.08 \%$ strain, (b) $3.6 \%$ strain and (c) $6 \%$ strain

Fig. 11 shows that the directions of stresses did not change from the beginning to the end of the applied displacement for the MMCs, reinforced with circular particles. But when the reinforced particle was triangle, the first principal stresses were in the direction of strain application at the start of the displacement (Fig. 12 (a)). With the increase of the displacement (Fig. 12 (b)), the direction of the stresses changed and the magnitude increased. The direction of the stresses changed mainly around the two sides of the trianular particle as well as in the matrix just above the particle. The first principal stresses around the sides became parallel to the sides. The stresses in the matrix above the particle rotated away from the sides of the triangle. A similar trend was continued with further increase in the applied displacement (Fig. 12 (c)).

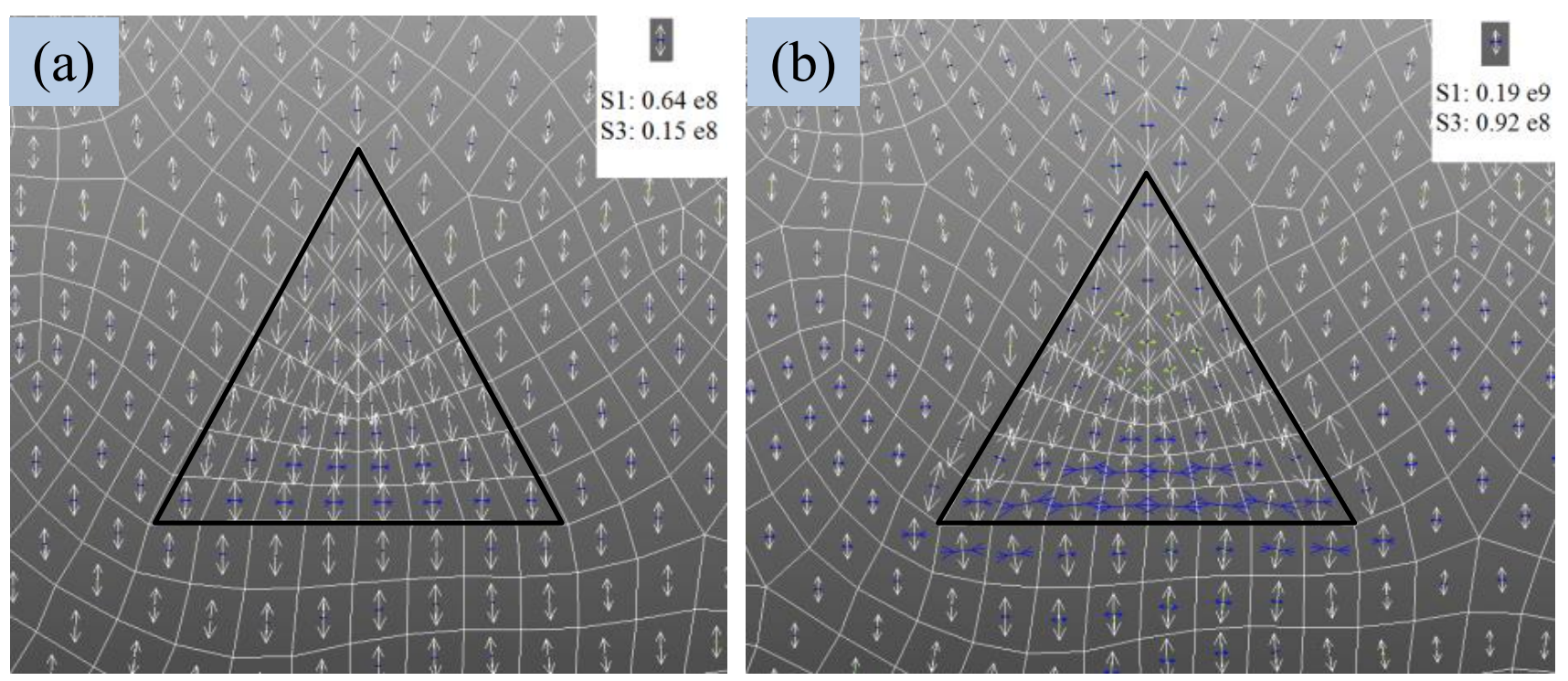




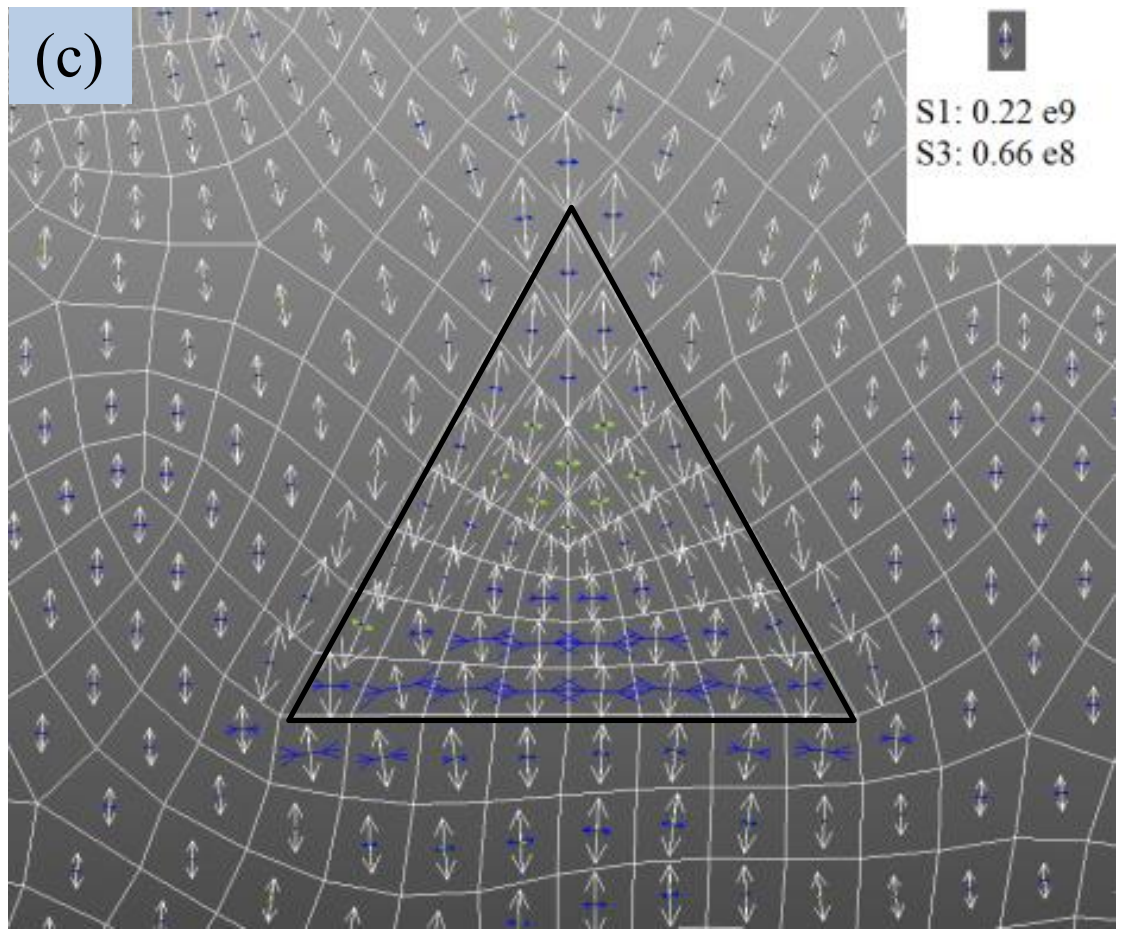

Fig. 12 Stress vector plot for $12 \mu \mathrm{m}-15 \%$ triangular particle at (a) $0.08 \%$ strain, (b) $3.5 \%$ strain and (c) $6 \%$ strain

Fig. 13 shows the stress distribution in the MMC, reinforced with square particles at different steps of displacement. In this case, no considerable variation of directions of stresses was noted from the beginning to the end of the applied displacement. In the case of rectangular particles (Fig. 14), a trend of divergence of stresses was noted in the matrix, at the top and bottom sides of the particles. The stress distribution was similar to the pattern of magnetic field around a rectangular magnet. This trend was started at the start of the applied displacement and continued until the end of the displacement.
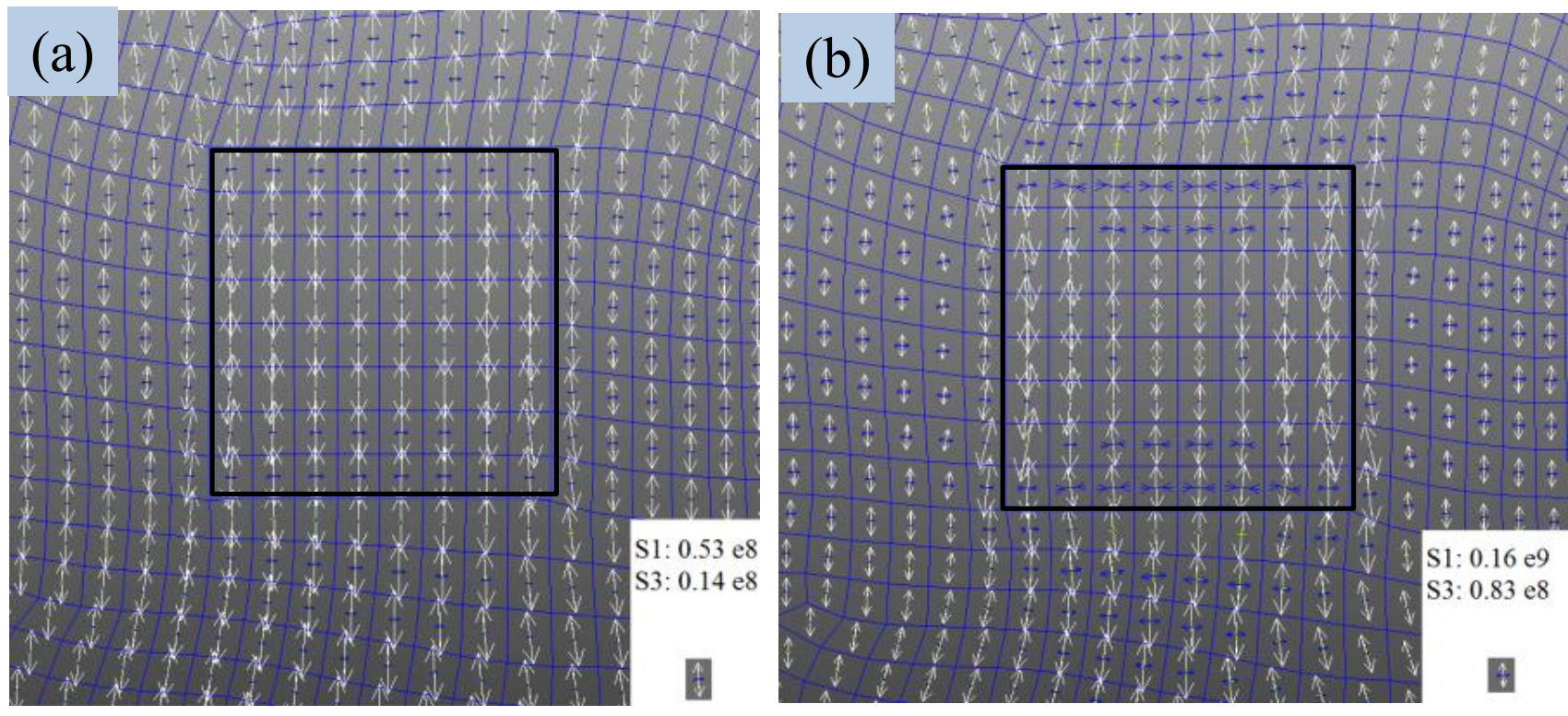


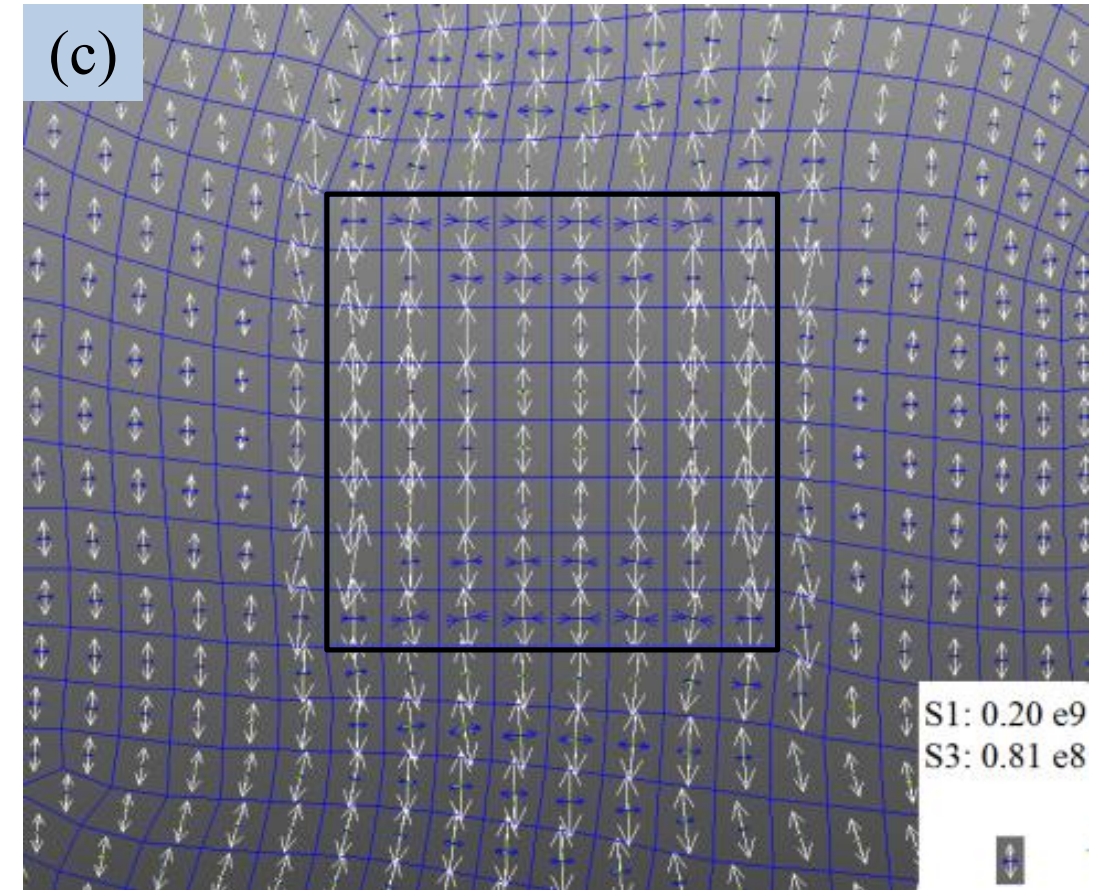

Fig. 13 Stress vector plot for $10 \mu \mathrm{m}-15 \%$ square particle at (a) $0.08 \%$ strain, (b) $2.9 \%$ strain and (c) $6 \%$ strain

When all the shapes were compared, it was seen that the highest first principal stress was generated in MMC with rectangular particle. In addition, the difference between stresses in matrix and reinforcement materials was maximum for this composite. It is clear from Figs. 11, 12, 13 and 14 that the MMCs with rectangular reinforcements showed highest capability of transferring loads from the matrix material to reinforcement particles, in the loading direction.

However, the triangular particle also carried the loads across the loading direction through the bottom side of the particle and a significant presence of third principal stresses were noted at this side of the particle (Fig. 12). In the case of the square particle, it carried the compressive stresses by the top and bottom side of the particle (Fig. 13). The circular particle also carried the compressive stresses through its middle part, across the loading direction (Fig. 11). 

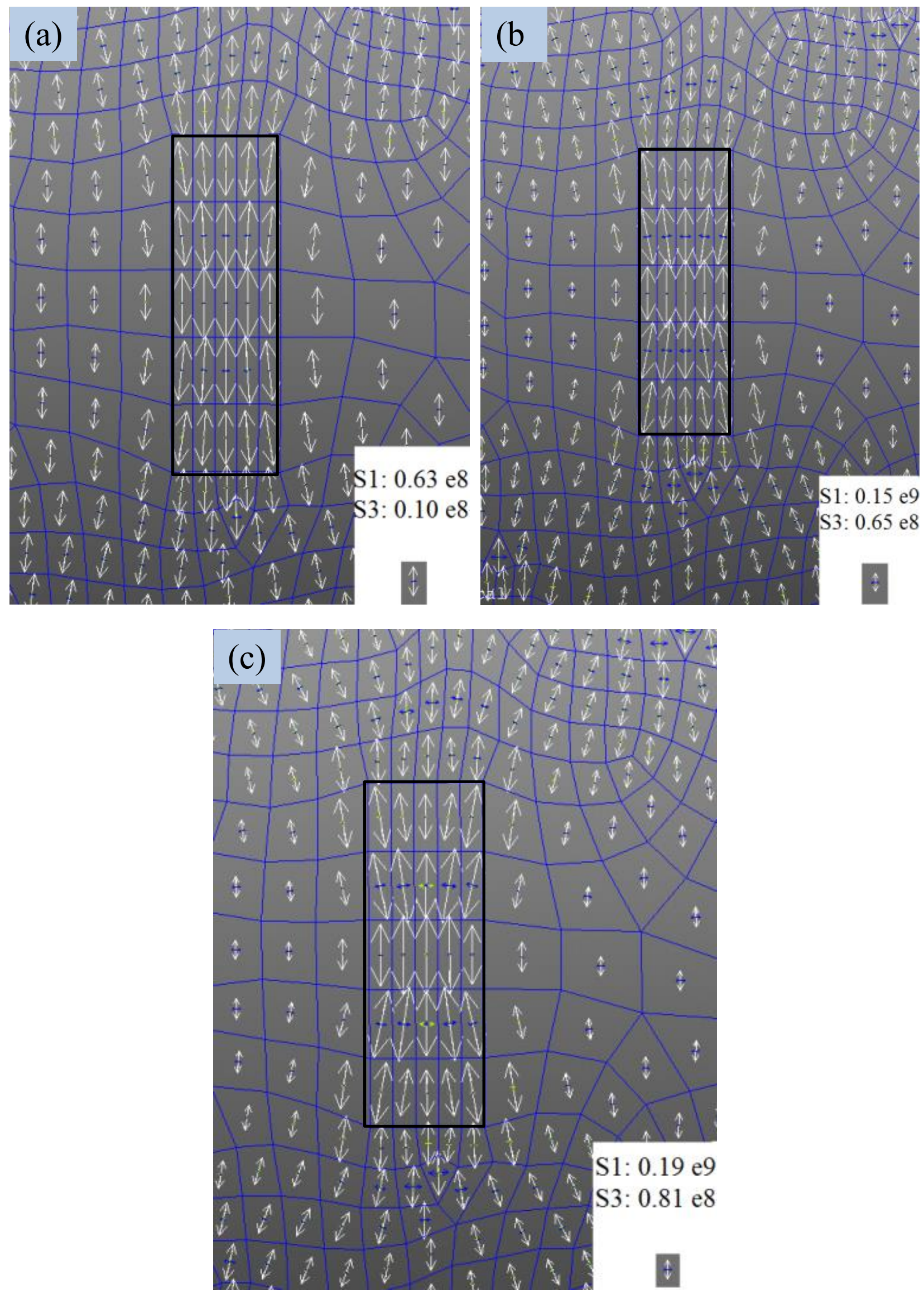

Fig. 14 Stress vector plot for $6 \mu \mathrm{m}-15 \%$ rectangular particle at(a) $0.08 \%$ strain, (b) $2.3 \%$ strain and (c) $6 \%$ strain 


\subsection{Development of plastic zone}

\subsubsection{Effect of reinforcement content}

To investigate the effect of reinforcement content on plasticity, the composites with $12 \mu \mathrm{m}$-diametre circular particles were selected; von Mises total strain was plotted for all three different reinforcement contents (Fig. 15). The figure shows that the von Mises stress developed in the matrix partially but symmetrically around the reinforced particles. As the percentage of the reinforcement content increased, the von Mises strain increased and spread across more areas. Very high von Mises strain was noted around the particles when the reinforcement content increased to $20 \%$. This explained the higher stiffness of the MMCs with higher reinforcement contents.

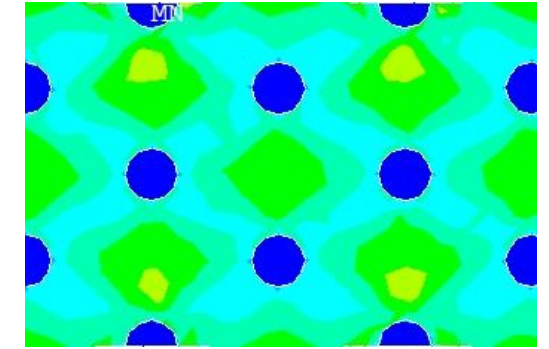

$12 \mu \mathrm{m}-10 \%$

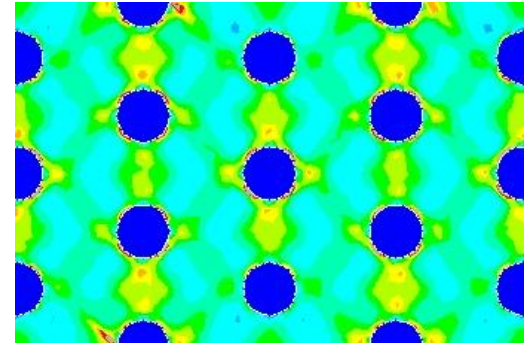

$12 \mu \mathrm{m}-15 \%$

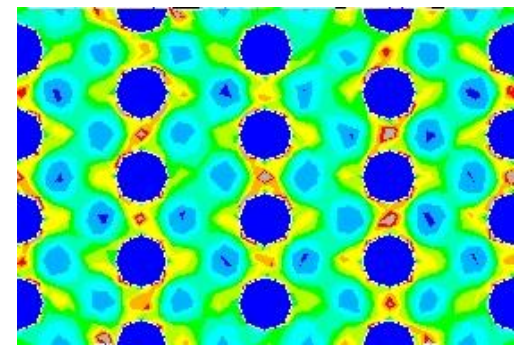

$12 \mu \mathrm{m}-20 \%$

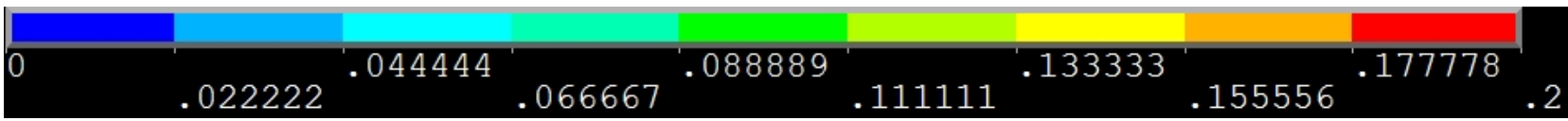

Fig. 15 von Mises total strains in composite with $12 \mu \mathrm{m}$ diameter circular particles

\subsection{Effect of size}

To investigate the effect of particle size on plasticity, the composites with circular particles and $15 \%$ reinforcement content were selected; von Mises total strain was plotted for all sizes (Fig 16). The figure shows that the von Mises stress developed in the matrix partially but symmetrically around the reinforced particles. With the reduction of particle size, the von Mises strain increased and spread uniformly throughout the matrix material. Almost all the matrix materials were uniformly strained when the particle size reduced to $6 \mu \mathrm{m}$-diametre; though, little higher strain band was noted in line with the particles, vertical to the applied displacement. The reduction of particles' size, increased the particles' total contact surface which consequently, increased the total transferred loads to these rigid particles. This explained the better properties of MMCs when the size of the particles was smaller. 


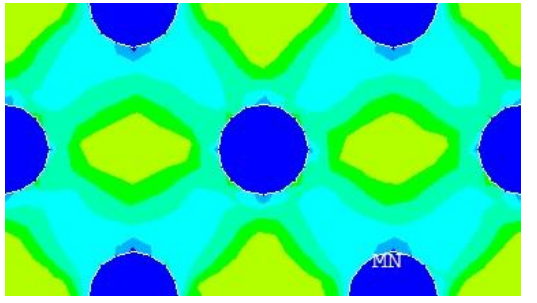

$24 \mu \mathrm{m}-15 \%$

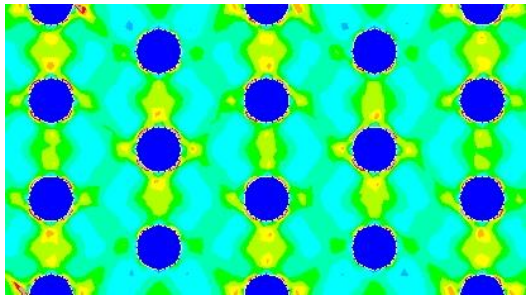

$12 \mu \mathrm{m}-15 \%$

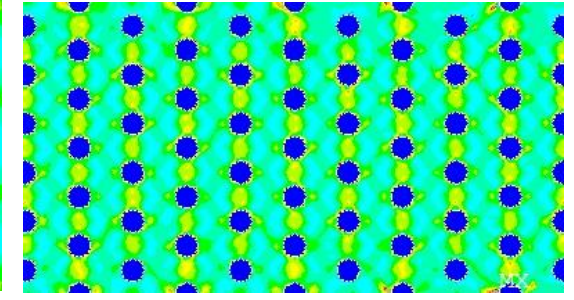

$6 \mu \mathrm{m}-15 \%$

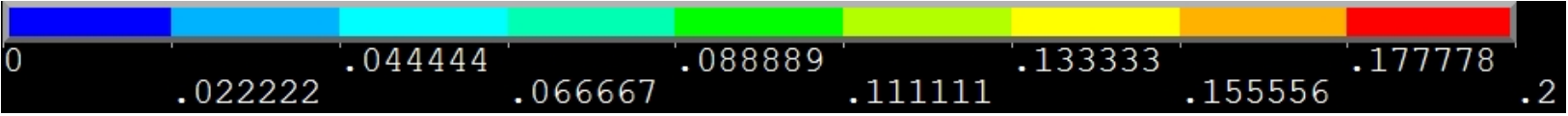

Fig. 16 von Mises total strain plot for composites with $15 \%$ circular particles

\subsection{Effect of shape}

The effects of particle's shape on plasticity of MMCs, is shown in Fig. 17. It shows that the von Mises stress developed in the matrix partially but symmetrically around the reinforced particles for all of the cases. The spread and amount of strain depended on the shape of the particles. The most widely distributed strain was noted for the MMC with rectangular particles then followed by square to triangular and to circular particles, in order of less strain distribution.

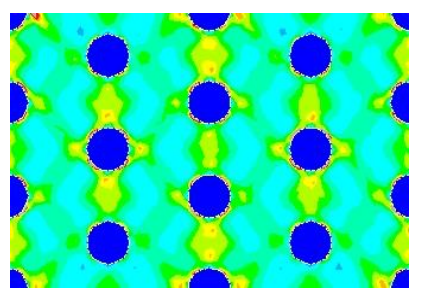

Circle

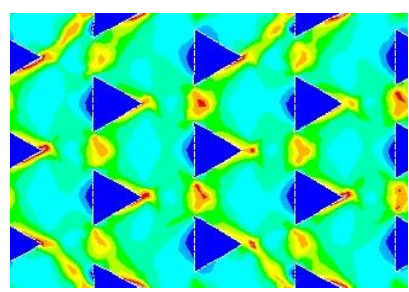

Triangle

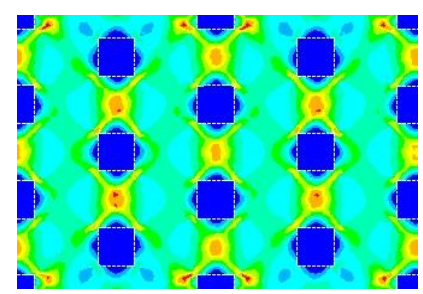

Square

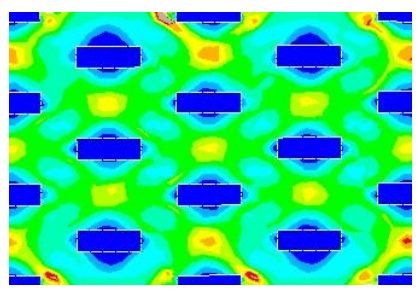

Rectangle

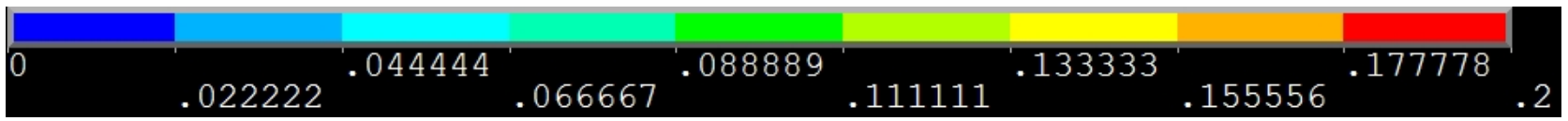

Fig. 17 von Mises total strain plot for composites with medium size particles-15\% volume

In above figure two major factors that were involved in the composite behaviours can be observed. The first factor was the effective sides of the particles that limit the movements of the dislocations. As can be seen, circular particles did not have such a factor and the areas around the circular particles were showing large strains; this changed in triangular particles to one effective side that limited the dislocations, and as shown, the minimum strain area was extended around that effective side. Square and rectangular particles, each had four effective sides with minimum strain areas all around them. The rectangular particles had more perimeters; therefore, bigger of the minimal strain areas between the two shapes. This made the composite more rigid by limiting the dislocation movements in tensile condition. 
The second factor was the distance between the particles. As the particles were located closer to each other, the matrix material between them became narrower and therefore showed higher strain concentration in that area. This strain concentration was reduced as the shapes changed to rectangle or circle, which provided bigger and better distributed strain areas between the particles. The first factor appeared to be a more conclusive criterion when comparing the composites with different particle shapes.

\subsection{Stiffness comparison}

In table 2, all nine study cases of MMCs with circular particle were arranged based on their stress values for a constant applied strain. It showed that the stiffness of the composites increased with the decrease of the particle size and the increase of the reinforcement content. The stiffness of MMCs depended on the amount of the loads transferred through their hard particles. The transfer of these loads also depended on the amount of the interface between the matrix material and hard particles. This interface, or total surface of contact ( $\mathrm{Sc}$ ), was calculated in Equation 2 by using the perimeter of the particles and their content in the composite.

Table 2 shows that the stiffness increased with the increase of the interface length for most of the cases. However, this trend was not always true. For example, the length of interface for MMC with $15 \%$ content of $6 \mu \mathrm{m}$ particles $(407.15 \mu \mathrm{m})$ was higher than that of MMC with $20 \%$ content of $12 \mu \mathrm{m}$ particles $(361.91 \mu \mathrm{m})$, but the load carrying capacity of the latter was higher among these two MMCs. In addition, though MMC with $20 \%$ content of $24 \mu \mathrm{m}$ particles and MMC with $10 \%$ content of $6 \mu \mathrm{m}$ had similar lengths of interface but the former showed higher stiffness. Therefore, it is clear that the length of matrix-particle interface was not the only factor that contributed to the strengthening mechanism. There are studies that showed that the properties of the matrix materials also contribute to the strengthening mechanism (Hall, Wayne Jones et al. 1994, Milan and Bowen 2004). High reinforcement content $(20 \%)$ increases the number of particles which apply higher resistance against the deformation of matrix material and induces strain hardening to matrix material. In addition, it also increases the length of interface. On the other hand, when the particle size reduces and the reinforcement content is constant, the ability for the particles to resist the deformation of matrix material reduces and the particles tend to move with the matrix material (Pramanik, Zhang et al. 2007). Thus, the matrix material experiences mush less strain hardening with smaller particles compare to that of bigger particles. The strengthening of MMCs occurs mainly by increased length of interface when the reinforcement particles are smaller. Therefore, the content and size of reinforcements contribute to the strengthening mechanism differently. It seems that the combined effects of matrix 
material hardening and load transfer capability of MMC with $20 \%$ content of $12 \mu \mathrm{m}$ particles made this MMC stronger than that of MMC with $15 \%$ content of $6 \mu \mathrm{m}$ particles. For the similar reasons MMC with $20 \%$ content of $24 \mu \mathrm{m}$ particles was stronger than MMC with $10 \%$ content of $6 \mu \mathrm{m}$.

\begin{tabular}{|c|c|c|c|c|}
\hline Stress (MPa) & Composite & \multirow[t]{10}{*}{ Max } & Absolute Increase & $\mathrm{Sc}(\mu \mathrm{m})$ \\
\hline 294 & $6 \mu \mathrm{m}-20 \%$ & & $30.9 \%$ & 723.82 \\
\hline 289 & $12 \mu \mathrm{m}-20 \%$ & & $28.4 \%$ & 361.91 \\
\hline 288 & $6 \mu m-15 \%$ & & $28.0 \%$ & 407.15 \\
\hline 285 & $12 \mu \mathrm{m}-15 \%$ & & $26.7 \%$ & 203.58 \\
\hline 283 & $24 \mu m-20 \%$ & & $25.8 \%$ & 180.96 \\
\hline 279 & $6 \mu m-10 \%$ & & $24.2 \%$ & 180.96 \\
\hline 279 & $24 \mu \mathrm{m}-15 \%$ & & $24.1 \%$ & 101.79 \\
\hline 279 & $12 \mu \mathrm{m}-10 \%$ & & $24.0 \%$ & 90.48 \\
\hline 277 & $24 \mu \mathrm{m}-10 \%$ & & $23.3 \%$ & 45.24 \\
\hline
\end{tabular}

Table 2- Stiffness comparison - composites with circular particles

$$
S_{c}=\text { Particle perimeter } \times \text { No. of particles } \times \frac{\text { Volume percentage }}{100}
$$

Similar trend was also noted for MMCs with triangular, square and rectangular particles, as shown in tables 3, 4 and 5, respectively. Similarly, the combinations of content and size of the particles with strain hardening of the matrix material contributed significantly to the strengthening of the MMCs.

\begin{tabular}{|c|c|c|c|c|}
\hline Stress (MPa) & Composite & \multirow{10}{*}{$\operatorname{Max}$} & Absolute Increase & Sc \\
\hline 324 & $8 \mu \mathrm{m}-20 \%$ & & $43.9 \%$ & 930.82 \\
\hline 315 & $16 \mu \mathrm{m}-20 \%$ & & $40.1 \%$ & 465.41 \\
\hline 298 & $8 \mu m-15 \%$ & & $32.5 \%$ & 523.58 \\
\hline 293 & $16 \mu \mathrm{m}-15 \%$ & & $30.2 \%$ & 261.79 \\
\hline 287 & $32 \mu \mathrm{m}-20 \%$ & & $27.6 \%$ & 232.70 \\
\hline 282 & $32 \mu \mathrm{m}-15 \%$ & & $25.3 \%$ & 130.90 \\
\hline 282 & $8 \mu \mathrm{m}-10 \%$ & & $25.2 \%$ & 232.70 \\
\hline 280 & $16 \mu \mathrm{m}-10 \%$ & & $24.7 \%$ & 116.35 \\
\hline 279 & $32 \mu \mathrm{m}-10 \%$ & & $24.2 \%$ & 58.18 \\
\hline
\end{tabular}

Table 3 - Stiffness comparison - composites with triangular particles

\begin{tabular}{|c|c|c|c|c|}
\hline Stress (MPa) & Composite & \multirow[t]{10}{*}{ Max } & absolute Increase & Sc \\
\hline 347 & $5 \mu \mathrm{m}-20 \%$ & & $54.5 \%$ & 816.69 \\
\hline 340 & $10 \mu \mathrm{m}-20 \%$ & & $51.4 \%$ & 408.35 \\
\hline 305 & $5 \mu m-15 \%$ & & $35.8 \%$ & 459.39 \\
\hline 293 & $10 \mu \mathrm{m}-15 \%$ & & $30.6 \%$ & 229.69 \\
\hline 285 & $21 \mu m-20 \%$ & & $26.7 \%$ & 204.18 \\
\hline 282 & $5 \mu m-10 \%$ & & $25.3 \%$ & 204.17 \\
\hline 282 & $21 \mu \mathrm{m}-15 \%$ & & $25.7 \%$ & 114.85 \\
\hline 281 & $10 \mu \mathrm{m}-10 \%$ & & $24.8 \%$ & 102.09 \\
\hline 280 & $21 \mu \mathrm{m}-10 \%$ & & $24.3 \%$ & 51.05 \\
\hline
\end{tabular}

Table 4 - Stiffness comparison - composites with square particles 


\begin{tabular}{|c|c|c|c|c|}
\hline Stress (MPa) & Composite & \multirow[t]{10}{*}{ Max } & absolute Increase & Sc \\
\hline 377 & $3 \mu \mathrm{m}-20 \%$ & & $67.7 \%$ & 943.10 \\
\hline 357 & $6 \mu \mathrm{m}-20 \%$ & & $58.7 \%$ & 471.55 \\
\hline 316 & $3 \mu m-15 \%$ & & $40.4 \%$ & 530.50 \\
\hline 308 & $6 \mu \mathrm{m}-15 \%$ & & $37.1 \%$ & 265.25 \\
\hline 292 & $12 \mu m-20 \%$ & & $29.8 \%$ & 235.78 \\
\hline 285 & $3 \mu \mathrm{m}-10 \%$ & & $26.2 \%$ & 235.78 \\
\hline 284 & $12 \mu \mathrm{m}-15 \%$ & & $26.8 \%$ & 132.62 \\
\hline 283 & $6 \mu \mathrm{m}-10 \%$ & & $26.1 \%$ & 117.89 \\
\hline 281 & $12 \mu \mathrm{m}-10 \%$ & & $24.9 \%$ & 58.94 \\
\hline
\end{tabular}

Table 5 - Total surface comparison - composites with rectangular particles

\section{$\underline{3.5 \text { Compare with rule of mixture (ROM) }}$}

The rule of mixture is the simplest way to calculate properties of composite materials which only accounts volume or mass percentage of reinforcements. Based on the properties of matrix and reinforced materials the Young's modulus of the MMCs reinforced with 10, 15 and 20 percentage reinforcements are 104.44, 120.86 and $137.28 \mathrm{GPa}$ respectively. The simulated results based on the circular shape particle with $12 \mu \mathrm{m}$ diameter the Young's modulus were 93.02, 99.03 and 106.18 GPa respectively. This shows that the Young's modulus of the MMCs increases with the increase of the content of the reinforcement. This trend is very similar to the primary results obtained in this investigation. In addition, it seems that rule of mixture over estimates the Young's modulus of the MMCs for the considered condition.

\section{Discussion}

There is no doubt that the presence of reinforcement particles up to a certain amount improved the mechanical properties of MMCs. 20\% reinforcement content strengthened MMCs due to the increase of the transferred loads, from the matrix material to the reinforcement particles. This also increased resistance to the flow of matrix material (Chawla, Andres et al. 1998, Milan and Bowen 2004, Pramanik, Zhang et al. 2007, Pramanik, Zhang et al. 2008). The decrease of particle size increased the interface between the matrix material and reinforcements. This facilitated the transfer of the loads from the matrix material to the reinforcement particles. Particles acted just like obstacles against the movement of matrix during plastic deformation. The yield strength and plastic work hardening rate of the composites increased with decrease in particle size (Yan, Geng et al. 2007). The composite's strength increased as more tension for the flow of matrix was required (Al-Qutub, Allam et al. 2006). In addition, amount of work hardening was inversely proportional to the particle size and directly proportional to flow stress. Therefore, as the size of the particles decreased, work hardening increased, which in turn led to a higher flow stress (Al-Qutub, Allam et al. 2006). The bigger particles, had shorter 
interface length but displayed more resistance to the movement of matrix material and introduced higher strain hardening in the matrix material. However, the strain hardening played bigger role in strengthening MMCs when the shape of the reinforcements came into the scene in addition to the size and reinforcement content (Chawla and Shen 2001, Ganesh and Chawla 2004, Sun, Song et al. 2011).

The results obtained in this investigation has similarities to the results obtained experimentally by several researchers, such as the mechanical properties, like tensile strength, of MMCs decreased for a given volume fraction as reinforcement particle size increased (Hall, Wayne Jones et al. 1994, Chawla, Andres et al. 1998, Varma, Kamat et al. 2001, Ganesh and Chawla 2004, Milan and Bowen 2004, Narayanasamy, Ramesh et al. 2009, Wang, Song et al. 2011). Narayanasamy et al., (Narayanasamy, Ramesh et al. 2009) evaluated the effect of SiC particle size on the workability of Al-SiC composite. It was found that the larger $\mathrm{SiC}$ particle $(120 \mu \mathrm{m})$ gave higher strain hardening index and lower strength coefficient, due to a better load transfer rate of $\mathrm{SiC}$ to the aluminium matrix, compared to a smaller particle size. Milan et al., (Milan and Bowen 2004) performed tensile test on T1-A12124 and Al6061, reinforced with silicon carbide particles $\left(\mathrm{SiC}_{\mathrm{P}}\right)$, and noted that the increase of particle fraction and/or matrix strength increased strength and decreased ductility. On the other hand, an increase in particle size reduced strength and increased the composite ductility. This also noted in this numerical analysis for certain volume percent and shape of the reinforced particles. Tables $2-5$ have presented those results. In addition, O'Donnell et al., (O'Donnell and Looney 2001) and Narayanasamy et al., (Narayanasamy, Ramesh et al. 2009) noted that the composites with bigger particle had better tensile strength than those with the smaller particle for 10 and $20 \%$ volume contents. Therefore, the MMCs reinforced with the smallest reinforcement particles did not always give the highest strength. Rahimian et al., (Rahimian, Parvin et al. 2010) experimentally studied properties of aluminium matrix composite considering the particle size and volume fraction of alumina and they found finer particle size of alumina presented greater yield strength of composites. In addition, an increase in the volume percentage, up to $10 \%$, was in favour of the yield strength but above $10 \%$ had reverse effect on the strength of the composites.

A direct comparison of the results obtained from above investigation with the experimentally obtained results is not possible because the experimental arrangement similar to this numerical analysis was never performed. It addition, (i) it is not easy to manufacture MMCs reinforced with particles of a particular shape and (ii) arranging MMCs with the configurations discussed in the investigation is very expensive and difficult. However, a qualitative comparison with experimental studies can be presented. 
Experimental investigations performed by many researchers (Chawla, Andres et al. 1998, Chen and Chao 2000, Kok 2005, Jamaati, Amirkhanlou et al. 2011), reported that stiffness of MMCs increases with the increase of the volume fraction of the reinforced particles. Jamaati et al. (Jamaati, Amirkhanlou et al. 2011) experimentally found that when the proper bonding and distribution of reinforced particles are achieved the tensile strength of the composite strip with larger particle size became less than the composite with smaller particle size (Chawla, Andres et al. 1998, Kok 2005).

In figure 18 (a) experimentally obtained stress-strain curves for different particle sizes have been presented based on the ref (Doel \& Bowen, 1996). It shows that the shape of stress strain curves are very similar to what obtain in this study. It also shows that bigger particle sizes gives higher stiffness to the MMCs. Figure 18 (b) compares experimentally (Ibrahim et al.199)1obtained Young's modulus with that obtain from the simulation in this study when the content of reinforcement varies. It shows that the Young's modulus increases with the increase of reinforcement content, and the experimental and simulated results increase in parallel with the increase of reinforcement content. In this case, simulated results slightly over estimate Young's modulus which may be due to irregular shape and non-uniform distribution of reinforcements for the experimental case.
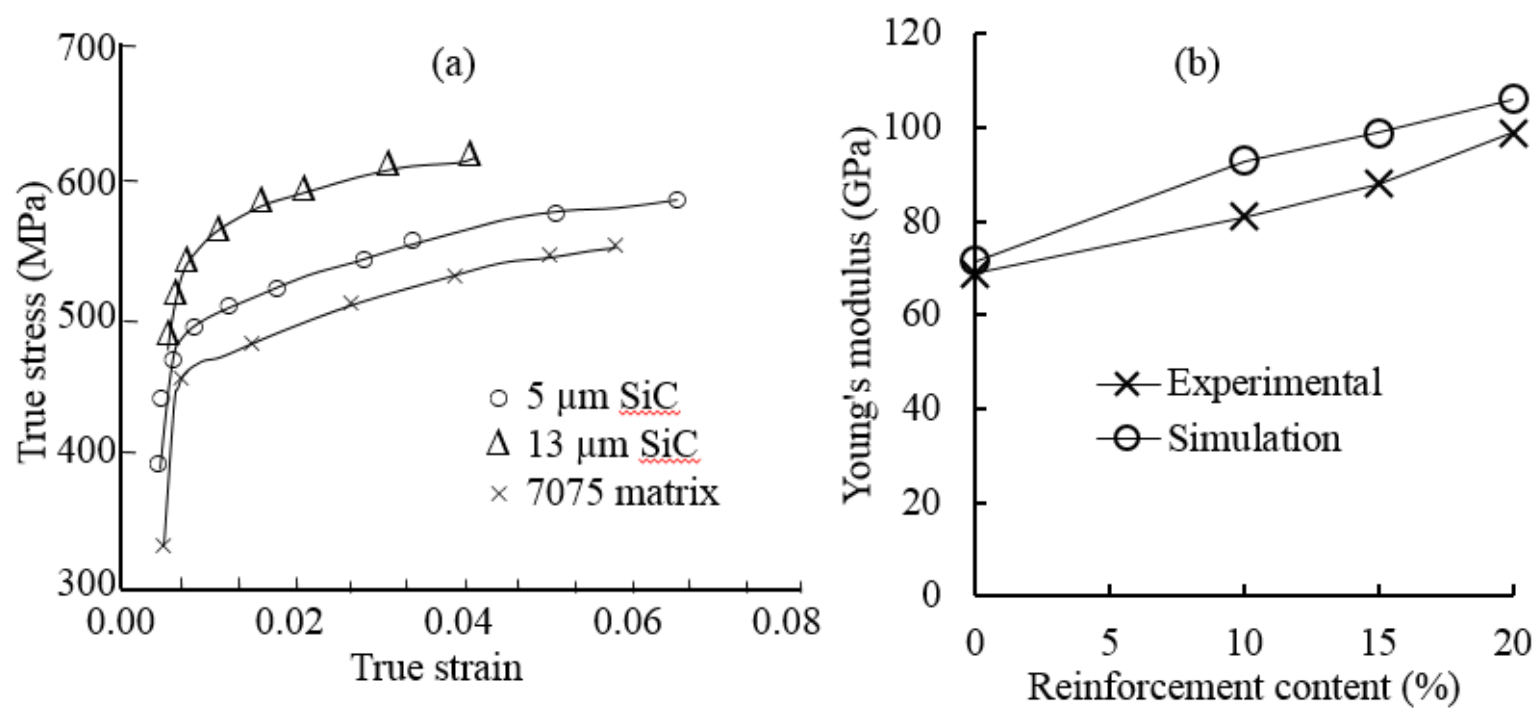

Fig. 18 Comparison of experimental results with simulated results (a) stress-strain curves for different $\underline{\text { sizes of reinforcements and (b) effect of reinforcement content on Young's modulus for experimental }}$ and simulated results.

\section{Conclusion}


Based on the FEA analyses of MMCs with four different shapes of particles, each with three different sizes and three different volume percentages, total thirty six study cases were investigated under a constant positive displacement and the following conclusions were drawn:

(a) The effects of shape and size of the reinforcement particles on the tensile properties of MMCs were negligible when the reinforcement content was $10 \%$.

(b) The MMCs with rectangular particles showed highest stiffness, compared to the other MMCs under similar conditions. Also, strain pattern was most widely and evenly distributed in the matrix material and around the rectangular particles.

(c) The first principal stresses acted along the direction of the applied displacement and their direction remained unchanged for all of the cases, except for the MMCs with triangular particles. In these cases, the stresses around the interface tended to align with the two sides of the triangular particles. Reasonably bigger third principal stresses were noted around the bottom interface of the triangle. The rectangular particles experienced the highest first principal stresses among all other shapes considered in this study. Thus, the MMCs with rectangular particles showed the highest stiffness.

(d) The stiffness of MMCs not only depended on the length of the interface, which facilitated the transfer of the loads from matrix material to particles, but also on the state of the matrix material which was influenced by the shape, size and reinforcement content.

(e) There was an optimum combination of shape, size and reinforcement content for which the highest stiffness of MMCs could be achieved.

\section{Reference}

Al-Qutub, A. M., I. M. Allam and T. W. Qureshi (2006). "Effect of sub-micron Al2O3 concentration on dry wear properties of 6061 aluminum based composite." Journal of Materials Processing Technology 172(3): 327-331.

Chawla, N., C. Andres, J. W. Jones and J. E. Allison (1998). "Effect of SiC volume fraction and particle size on the fatigue resistance of a $2080 \mathrm{Al} / \mathrm{SiCp}$ composite." Metallurgical and Materials Transactions A: Physical Metallurgy and Materials Science 29(11): 2843-2854.

Chawla, N. and Y. L. Shen (2001). "Mechanical behavior of particle reinforced metal matrix composites." Advanced Engineering Materials 3(6): 357-370.

Chen, C.-Y. and C.-G. Chao (2000). "Effect of particle-size distribution on the properties of highvolume-fraction SiC p-Al-based composites." Metallurgical and Materials Transactions A 31(9): 23512359.

Doel, T. J. A., and P. Bowen. (1996). "Tensile properties of particulate-reinforced metal matrix composites." Composites Part A: Applied Science and Manufacturing 27(8): 655-665.

Ganesh, V. V. and N. Chawla (2004). "Effect of Reinforcement-Particle-Orientation Anisotropy on the Tensile and Fatigue Behavior of Metal-Matrix Composites." Metallurgical and Materials Transactions A: Physical Metallurgy and Materials Science 35 A(1): 53-61. 
Hall, J. N., J. Wayne Jones and A. K. Sachdev (1994). "Particle size, volume fraction and matrix strength effects on fatigue behavior and particle fracture in 2124 aluminum-SiCp composites." Materials Science and Engineering: A 183(1-2): 69-80.

Huang, H. and M. Bush (1997). "Finite element analysis of mechanical properties in discontinuously reinforced metal matrix composites with ultrafine micro structure." Materials Science and Engineering: A 232(1): 63-72.

Jamaati, R., S. Amirkhanlou, M. R. Toroghinejad and B. Niroumand (2011). "Effect of particle size on microstructure and mechanical properties of composites produced by ARB process." Materials Science and Engineering: A 528(4): 2143-2148.

Ibrahim, I. A., F. A. Mohamed and E. J. Lavernia. (1991). "Particulate reinforced metal matrix composites - a review." Journal of Materials Science 26 (5), 1137-1156.

Kok, M. (2005). "Production and mechanical properties of Al 2 O 3 particle-reinforced 2024 aluminium alloy composites." Journal of Materials Processing Technology 161(3): 381-387.

Milan, M. T. and P. Bowen (2004). "Tensile and fracture toughness properties of SiCp reinforced Al alloys: Effects of particle size, particle volume fraction, and matrix strength." Journal of Materials Engineering and Performance 13(6): 775-783.

Narayanasamy, R., T. Ramesh and M. Prabhakar (2009). "Effect of particle size of SiC in aluminium matrix on workability and strain hardening behaviour of P/M composite." Materials Science and Engineering A 504(1-2): 13-23.

O'Donnell, G. and L. Looney (2001). "Production of aluminium matrix composite components using conventional PM technology." Materials Science and Engineering: A 303(1-2): 292-301.

Prabu, S. B., L. Karunamoorthy and G. Kandasami (2004). "A finite element analysis study of micromechanical interfacial characteristics of metal matrix composites." Journal of materials processing technology 153: 992-997.

Pramanik, A., L. Zhang and J. Arsecularatne (2007). "An FEM investigation into the behavior of metal matrix composites: Tool-particle interaction during orthogonal cutting." International Journal of Machine Tools and Manufacture 47(10): 1497-1506.

Pramanik, A., L. Zhang and J. Arsecularatne (2007). "Micro-indentation of metal matrix compositesan FEM analysis." Key Eng Mater 340: 341.

Pramanik, A., L. Zhang and J. Arsecularatne (2008). "Deformation mechanisms of MMCs under indentation." Composites Science and Technology 68(6): 1304-1312.

Rahimian, M., N. Parvin and N. Ehsani (2010). "Investigation of particle size and amount of alumina on microstructure and mechanical properties of Al matrix composite made by powder metallurgy." Materials Science and Engineering: A 527(4): 1031-1038.

Sun, C., M. Song, Z. Wang and Y. He (2011). "Effect of particle size on the microstructures and mechanical properties of SiC-reinforced pure aluminum composites." Journal of Materials Engineering and Performance 20(9): 1606-1612.

Varma, V. K., S. V. Kamat, Y. R. Mahajan and V. V. Kutumbarao (2001). "Effect of reinforcement size on low strain yielding behaviour in $\mathrm{Al}-\mathrm{Cu}-\mathrm{Mg} / \mathrm{SiCp}$ composites." Materials Science and Engineering A 318(1-2): 57-64.

Wang, Z., M. Song, C. Sun and Y. He (2011). "Effects of particle size and distribution on the mechanical properties of SiC reinforced Al-Cu alloy composites." Materials Science and Engineering A 528(3): 1131-1137.

Yan, Y., L. Geng and A. Li (2007). "Experimental and numerical studies of the effect of particle size on the deformation behavior of the metal matrix composites." Materials Science and Engineering: A 448(1): 315-325.

Doel, T. J. A., and P. Bowen. (1996). "Tensile properties of particulate-reinforced metal matrix composites." Composites Part A: Applied Science and Manufacturing 27(8): 655-665. 
Ibrahim, I. A., F. A. Mohamed and E. J. Lavernia. (1991). "Particulate reinforced metal matrix composites - a review." Journal of Materials Science 26 (5), 1137-1156. 